Cochrane Database of Systematic Reviews

\title{
Immediate versus deferred delivery of the preterm baby with suspected fetal compromise for improving outcomes (Review)
}

Stock SJ, Bricker L, Norman JE, West HM

Stock SJ, Bricker L, Norman JE, West HM.

Immediate versus deferred delivery of the preterm baby with suspected fetal compromise for improving outcomes.

Cochrane Database of Systematic Reviews 2016, Issue 7. Art. No.: CD008968.

DOI: 10.1002/14651858.CD008968.pub3.

www.cochranelibrary.com 
TABLE OF CONTENTS

ABSTRAC

PLAIN LANGUAGE SUMMARY

SUMMARY OF FINDINGS

4

BACKGROUND

OBJECTIVES

METHODS

RESULTS

Figure 1.

Figure 2.

DISCUSSION

AUTHORS' CONCLUSIONS

ACKNOWLEDGEMENTS

REFERENCES

CHARACTERISTICS OF STUDIES

DATA AND ANALYSES

Analysis 1.1. Comparison $1 \mathrm{Immediate}$ delivery versus deferred delivery, Outcome 1 Extended perinatal mortality. ................

Analysis 1.2. Comparison $1 \mathrm{Immediate}$ delivery versus deferred delivery, Outcome 2 Death or disability at or after 2 years. ......

Analysis 1.3. Comparison $1 \mathrm{Immediate}$ delivery versus deferred delivery, Outcome 3 Stillbirth.

Analysis 1.4. Comparison $1 \mathrm{Immediate}$ delivery versus deferred delivery, Outcome 4 Neonatal mortality.

Analysis 1.5. Comparison 1 Immediate delivery versus deferred delivery, Outcome 5 Postneonatal mortality (> 28 days to discharge).

Analysis 1.6. Comparison $1 \mathrm{Immediate}$ delivery versus deferred delivery, Outcome 6 Death at or after 2 years of age.

Analysis 1.7. Comparison $1 \mathrm{Immediate}$ delivery versus deferred delivery, Outcome 7 Cord pH less than 7.0.

Analysis 1.8. Comparison $1 \mathrm{Immediate}$ delivery versus deferred delivery, Outcome 8 Apgar less than 7 at 5 minutes.

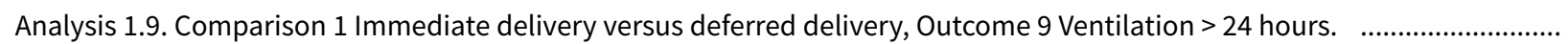

Analysis 1.10. Comparison $1 \mathrm{Immediate}$ delivery versus deferred delivery, Outcome 10 Convulsions.

Analysis 1.11. Comparison $1 \mathrm{Immediate}$ delivery versus deferred delivery, Outcome 11 Interventricular haemorrhage or germinal matrix haemorrhage.

Analysis 1.12. Comparison 1 Immediate delivery versus deferred delivery, Outcome 12 Necrotising enterocolitis. ..................

Analysis 1.13. Comparison $1 \mathrm{Immediate}$ delivery versus deferred delivery, Outcome 13 Periventricular leucomalacia or ventriculomegaly.

Analysis 1.14. Comparison 1 Immediate delivery versus deferred delivery, Outcome 14 Neurodevelopmental impairment at or after 2 years.

Analysis 1.15. Comparison $1 \mathrm{Immediate}$ delivery versus deferred delivery, Outcome 15 Cerebral palsy at or after 2 years of age.

Analysis 1.16. Comparison $1 \mathrm{Immediate}$ delivery versus deferred delivery, Outcome 16 Death or severe disability 6-13 years. ..

Analysis 1.17. Comparison 1 Immediate delivery versus deferred delivery, Outcome 17 Kaufman-ABC MPC.

Analysis 1.18. Comparison $1 \mathrm{Immediate}$ delivery versus deferred delivery, Outcome 18 Caesarean delivery.

Analysis 1.19. Comparison 1 Immediate delivery versus deferred delivery, Outcome 19 Subgroup analysis: death or disability at or after 2 years of age.

WHAT'S NEW

CONTRIBUTIONS OF AUTHORS

DECLARATIONS OF INTEREST

SOURCES OF SUPPORT

DIFFERENCES BETWEEN PROTOCOL AND REVIEW

INDEX TERMS 
[Intervention Review]

\section{Immediate versus deferred delivery of the preterm baby with suspected fetal compromise for improving outcomes}

Sarah J Stock ${ }^{1}$, Leanne Bricker ${ }^{2}$, Jane E Norman ${ }^{1}$, Helen M West ${ }^{3}$

1MRC Centre for Reproductive Health, University of Edinburgh Queen's Medical Research Centre, Edinburgh, UK. ${ }^{2}$ Corniche Hospital, Abu Dhabi, United Arab Emirates. ${ }^{3}$ Cochrane Pregnancy and Childbirth Group, Department of Women's and Children's Health, The University of Liverpool, Liverpool, UK

Contact: Sarah J Stock, MRC Centre for Reproductive Health, University of Edinburgh Queen's Medical Research Centre, Edinburgh, EH16 4TJ, UK. sarah.stock@ed.ac.uk.

Editorial group: Cochrane Pregnancy and Childbirth Group.

Publication status and date: New search for studies and content updated (no change to conclusions), published in Issue 7, 2016.

Citation: Stock SJ, Bricker L, Norman JE, West HM. Immediate versus deferred delivery of the preterm baby with suspected fetal compromise for improving outcomes. Cochrane Database of Systematic Reviews 2016, Issue 7. Art. No.: CD008968. DOI: 10.1002/14651858.CD008968.pub3.

Copyright ( 2016 The Cochrane Collaboration. Published by John Wiley \& Sons, Ltd.

\section{A B S T R A C T}

\section{Background}

Immediate delivery of the preterm fetus with suspected compromise may decrease the risk of damage due to intrauterine hypoxia. However, it may also increase the risks of prematurity.

\section{Objectives}

To assess the effects of immediate versus deferred delivery of preterm babies with suspected fetal compromise on neonatal, maternal and long-term outcomes.

\section{Search methods}

We searched the Cochrane Pregnancy and Childbirth Group's Trials Register (30 April 2016) and reference lists of retrieved studies.

\section{Selection criteria}

Randomised trials comparing a policy of immediate delivery with deferred delivery or expectant management in preterm fetuses with suspected in utero compromise. Quasi-randomised trials and trials employing a cluster-randomised design were eligible for inclusion but none were identified.

\section{Data collection and analysis}

Two review authors independently assessed trials for inclusion and risk of bias, extracted data and checked them for accuracy.

\section{Main results}

We included one trial of 548 women ( 588 babies) in the review. Women with pregnancies between 24 and 36 weeks' gestation took part. The study took place in 13 European countries, between 1993 and 2001. The difference in the median randomisation to delivery interval between immediate delivery and deferred delivery was four days (median: 0.9 (inter-quartile range (IQR) 0.4 to 1.3 ) days for immediate delivery, median: 4.9 (IQR 2.0 to 10.8) days in the delay group).

There was no clear difference in the primary outcomes of extended perinatal mortality (risk ratio (RR) $1.17,95 \%$ confidence interval (CI) 0.67 to 2.04, one trial, 587 babies, moderate-quality evidence) or the composite outcome of death or disability at or after two years of age (RR $1.22,95 \% \mathrm{Cl} 0.85$ to 1.75 , one trial, 573 babies, moderate-quality evidence) with immediate delivery compared to deferred delivery. 
The results for these outcomes are consistent with both appreciable benefit and harm. More babies in the immediate delivery group were ventilated for more than $\mathbf{2 4}$ hours (RR 1.54, 95\% Cl 1.20 to 1.97, one trial, 576 babies). There were no differences between the immediate delivery and deferred delivery groups in any other infant mortality outcome (stillbirth, neonatal mortality, postneonatal mortality $>\mathbf{2 8}$ days to discharge), individual neonatal morbidity or markers of neonatal morbidity (cord pH less than 7.00, Apgar less than seven at five minutes, convulsions, interventricular haemorrhage or germinal matrix haemorrhage, necrotising enterocolitis and periventricular leucomalacia or ventriculomegaly).

Some important outcomes were not reported, in particular infant admission to neonatal intensive care or special care facility, and respiratory distress syndrome. We were not able to calculate composite rates of serious neonatal morbidity, even though individual morbidities were reported, due to the risk of double counting infants with more than one morbidity.

More children in the immediate delivery group had cerebral palsy at or after two years of age (RR $5.88,95 \% \mathrm{Cl} 1.33$ to 26.02 , one trial, 507 children). There were, however, no differences in neurodevelopment impairment at or after two years ( $\mathrm{RR} 1.72,95 \% \mathrm{Cl} 0.86$ to 3.41 , one trial, 507 children), death at or after two years of age (RR 1.04, $95 \% \mathrm{Cl} 0.66$ to 1.63 , one trial, 573 children), or death or disability in childhood (six to 13 years of age) (RR $0.82,95 \% \mathrm{Cl} 0.48$ to 1.40, one trial, 302 children). More women in the immediate delivery group had caesarean delivery than in the deferred delivery group ( $\mathrm{RR} 1.15,95 \% \mathrm{Cl} 1.07$ to 1.24, one trial, 547 women, high-quality evidence). Data were not available on any other maternal outcomes.

There were several methodological weaknesses in the included study, and the level of evidence for the primary outcomes was graded high for caesarean section and moderate for extended perinatal mortality and death or disability at or after two years. The evidence was downgraded because the Cls for these outcomes were wide, and were consistent with both appreciable benefit and harm. Bias may have been introduced by several factors: blinding was not possible due to the nature of the intervention, data for childhood follow-up were incomplete due to attrition, and no adjustment was made in the analysis for the non-independence of babies from multiple pregnancies (39 out of 548 pregnancies). This study only included cases of suspected fetal compromise where there was uncertainty whether immediate delivery was indicated, thus results must be interpreted with caution.

\section{Authors' conclusions}

Currently there is insufficient evidence on the benefits and harms of immediate delivery compared with deferred delivery in cases of suspected fetal compromise at preterm gestations to make firm recommendations. There is a lack of trials addressing this question, and limitations of the one included trial means that caution must be used in interpreting and generalising the findings. More research is needed to guide clinical practice.

Although the included trial is relatively large, it has insufficient power to detect differences in neonatal mortality. It did not report any maternal outcomes other than mode of delivery, or evaluate maternal satisfaction or economic outcomes. The applicability of the findings is limited by several factors: Women with a wide range of obstetric complications and gestational ages were included, and subgroup analysis is currently limited. Advances in Doppler assessment techniques may diagnose severe compromise more accurately and help make decisions about the timing of delivery. The potential benefits of deferring delivery for longer or shorter periods cannot be presumed.

Where there is uncertainty whether or not to deliver a preterm fetus with suspected fetal compromise, there seems to be no benefit to immediate delivery. Deferring delivery until test results worsen or increasing gestation favours delivery may improve the outcomes for mother and baby.

There is a need for high-quality randomised controlled trials comparing immediate and deferred delivery where there is suspected fetal compromise at preterm gestations to guide clinical practice. Future trials should report all important outcomes, and should be adequately powered to detect differences in maternal and neonatal morbidity and mortality.

\section{PLAIN LANGUAGE SUMMARY}

\section{Immediate or delayed birth for a preterm fetus with suspected compromise}

\section{What is the issue?}

For a fetus who is not receiving enough oxygen or nutrients, the choice is to deliver the baby immediately (following a course of steroids to help the baby's lungs to mature) or to wait as long as is thought to be safe. This review looked at which option was better for mothers and babies.

\section{Why is this important?}

Waiting allows the baby to develop as much as possible and decreases the risks associated with being premature. Premature babies are more likely to have breathing difficulties, low body temperature, low blood sugar levels, infection and jaundice. Remaining in the womb may mean the baby's vital organs are affected by a lack of oxygen.

\section{What evidence did we find?}


We searched for evidence on 30 April 2016. This review includes one randomised study with 548 pregnant women (and 588 babies) with pregnancies between 24 and 36 weeks' gestation. The study took place in 13 countries in Europe, between 1993 and 2001 . Women were asked to take part if their doctor was concerned about the baby but unsure if immediate delivery was best. The women were randomly allocated to immediate delivery or delivery when the doctor thought it was necessary. There were a few problems with the design of the study which may have affected the results: women and doctors knew which group they were in, some families left the study, and twins were analysed as though they were unrelated babies. There was moderate-quality evidence for the main outcomes. Women only took part in the study if their doctor was not sure whether the baby needed to be born immediately or not. We do not know if the results apply when the doctor thinks that immediate birth or waiting was needed.

Most babies in the delayed delivery group stayed in the womb for four days longer than babies in the immediate delivery group. More women in the immediate delivery group had a caesarean section (high quality evidence) and more babies delivered immediately needed mechanical breathing support for longer than 24 hours. There was no clear difference between immediate and delayed delivery in the number of babies who died (around the time of birth, or in the days and months after) (moderate quality evidence). There was also no clear difference in the number of babies who showed signs of medical problems known to affect premature babies, such as bleeding in the brain. The number of children with cerebral palsy at age two was higher in the immediate delivery group but there was no difference in neurodevelopmental impairment at or after two years, death or disability at two years (moderate quality evidence), and death or disability in childhood (six to 13 years). Some important outcomes were not reported, such as going to the neonatal intensive care unit and breathing problems. We were not able to add up the number of babies with different illnesses to work out the total number of babies with an illness, as some babies might be counted more than once.

\section{What does this mean?}

For preterm babies with suspected compromise and uncertainty about whether to deliver or not, there appears to be no benefit to immediate delivery.

As there is only one trial, and it has flaws, we need to be careful how we apply this evidence. We still do not know how long it is best to wait, and if waiting is better at some gestational ages or for certain conditions causing compromise. Better methods for diagnosing problems may also help us to decide when it is best for the baby to be born.

Delayed delivery may be better for mothers and babies, but further large trials are needed to check if it makes a difference to rare outcomes, such as the number of babies who die. Future trials should be high quality and report all important outcomes. 


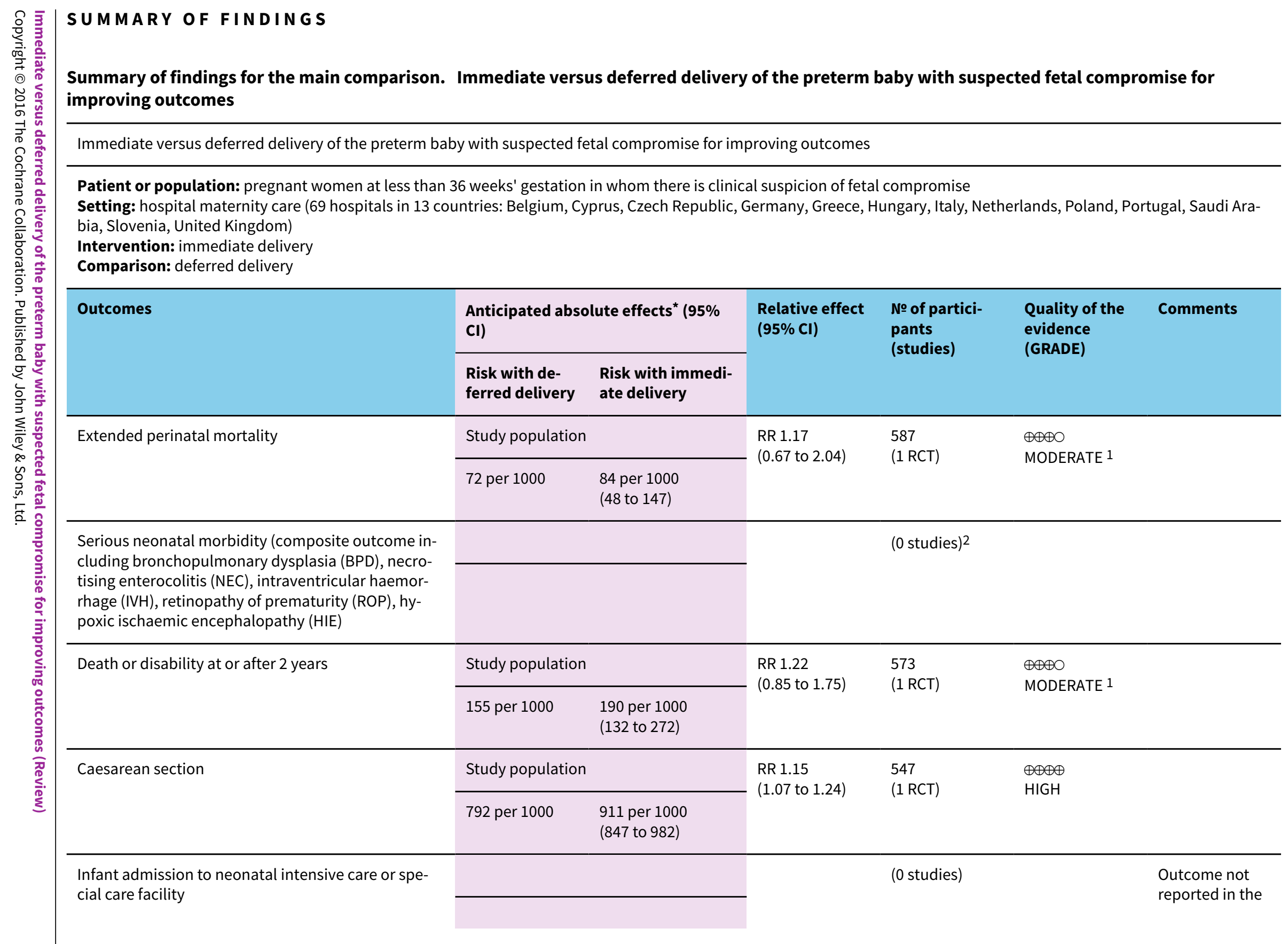

Patient or population: pregnant women at less than 36 weeks' gestation in whom there is clinical suspicion of fetal compromise

bia, Slovenia, United Kingdom)

Comparison: deferred delivery 
*The risk in the intervention group (and its $95 \% \mathrm{Cl}$ ) is based on the assumed risk in the comparison group and the relative effect of the intervention (and its $95 \% \mathrm{Cl}$ ).

Cl: Confidence interval; RR: Risk ratio

\section{GRADE Working Group grades of evidence}

High quality: we are very confident that the true effect lies close to that of the estimate of the effect

Moderate quality: we are moderately confident in the effect estimate: the true effect is likely to be close to the estimate of the effect, but there is a possibility that it is substantially different

Low quality: our confidence in the effect estimate is limited: the true effect may be substantially different from the estimate of the effect

Very low quality: we have very little confidence in the effect estimate: the true effect is likely to be substantially different from the estimate of effect

1 Wide $\mathrm{Cl}$ crossing the line of no effect

2 We were not able to calculate composite rates of serious neonatal morbidity, even though individual morbidities were reported in 1 RCT, due to the risk of double counting infants with more than one morbidity. 


\section{B A C K G R O U N D}

\section{Description of the condition}

Fetal compromise occurs when there is an inadequate oxygen or nutrient supply to the developing baby. This can be recognised by progressive alterations in the growth, metabolic, cardiovascular and behavioural parameters of the fetus, which represent increasing hypoxaemia and acidosis. The function of vital organs may be affected, leading to temporary or permanent damage or intrauterine death. Fetal compromise is most commonly a result of placental insufficiency, which occurs in approximately $3 \%$ of pregnancies (Alberry 2007). This is thought to originate from defective trophoblast invasion in the first trimester (Miller 2008), leading to increased placental vascular resistance that impairs oxygen and nutrient supply to the fetus. Other causes include congenital abnormality, isoimmunisation, intrauterine infection and twin-twin transfusion syndrome in monochorionic twins. The degree and progression of fetal compromise is variable, and is probably dependent on gestation, maternal factors and the nature and severity of the underlying cause (Miller 2008).

A number of interventions have been proposed as in utero treatments for fetal compromise, including calcium channel blockers, hormones, steroids, nutritional supplementation, oxygen therapy, plasma volume expansion, abdominal decompression, electrostimulation, betamimetics and bed rest. Many of these have been reviewed in other Cochrane reviews and none have been found to be effective in improving outcome (Hofmeyr 2012; Say 1996a; Say 1996b; Say 1996c; Say 1996d; Say 2001; Say 2003a; Say 2003b; Say 2003c). An exception is in cases of compromise due to twin-twin transfusion syndrome. This is a distinct condition where compromise arises due to vascular anastomoses in the placental circulation of monochorionic twins. In this situation there is some evidence that laser coagulation of anastomotic vessels improves perinatal outcome (Roberts 2014), hence we have excluded this group from this review. In all other situations leading to fetal compromise, in the absence of effective interventions, the mainstay of management is based on monitoring progression of fetal compromise and delivering the baby at a time that is thought to minimise risk to the infant. However, deciding the optimal timing for delivery of preterm babies with fetal compromise is often difficult.

The presentation of fetal compromise is variable. Recognition of the pregnancy at risk of fetal compromise may be based on clinical features, such as obstetric history or the presence of medical conditions associated with placental insufficiency. Abnormal fetal growth or liquor production may be found on abdominal palpation, or on ultrasound examination. A decrease in fetal movements may be perceived by the mother, or fetal heart rate abnormalities may be detected on cardiotocograph (CTG).

Several different methods can be used to assess fetal compromise including the following.

1. Serial ultrasound biometry (Bricker 2009), which can detect reduction in fetal growth velocity. This is often performed in conjunction with ultrasound assessment of amniotic fluid, which if reduced may reflect reduction in fetal urine production secondary to reduced renal blood flow, which occurs as a physiological response to poor placental blood flow.
2. Umbilical artery Doppler ultrasound (Alfirevic 2013), which can detect increased resistance or absent or reversed end-diastolic flow. This reflects increasing placental vascular resistance and damage.

3. Fetal arterial Doppler ultrasound (e.g. middle cerebral artery or aortic isthmus) (Alfirevic 2013), which can detect decreased resistance, indicative of brain sparing.

4. Fetal venous Doppler ultrasound (e.g. ductus venosus or inferior vena cava) (Alfirevic 2013). Abnormalities reflect pre-terminal impairment of cardiac function.

5. CTG (Grivell 2015), which can detect changes in fetal heart reactivity.

6. Computerised CTG (Guzman 1996), which can detect changes suggestive of fetal hypoxaemia and acidaemia.

7. Biophysical profile (Lalor 2008), which consists of CTG in combination with ultrasound to detect changes in fetal behaviour and reduction in amniotic fluid volume that can occur secondary to decreased renal blood flow and fetal urine production. The combination of CTG and amniotic fluid volume assessment alone is called the modified biophysical profile.

The diagnosis of fetal compromise, and the uncertainties in its management can be very distressing for women and their families. Suspected or proven fetal compromise is likely to increase anxiety about pregnancy outcome, and the need for intensive monitoring or admission can be disruptive and result in separation from the family.

\section{Description of the intervention}

Once fetal compromise is recognised, the options are immediate delivery (with or without awaiting 24 to 48 hours for administration of antenatal steroids to promote fetal lung maturity), or expectant management. Expectant management involves monitoring progression of fetal compromise and, if monitoring is sufficiently reassuring, either allowing pregnancy to continue to a certain gestational age or the onset of spontaneous labour, or delivering the fetus when it is thought that the degree of in utero compromise imminently jeopardises fetal well-being. Fetal monitoring can involve any of the methods described above, and a combination of methods is often used. Other Cochrane reviews (Alfirevic 2013; Grivell 2012; Lalor 2008; Nabhan 2008) focus on methods and frequency of assessing fetal compromise. Delivery is most often achieved by caesarean section, although occasionally induction of labour may be attempted.

\section{How the intervention might work}

Immediate delivery removes the baby from the hostile uterine environment, decreasing the risk of progressive damage due to hypoxia. However, these benefits must be offset against the risks of increased morbidity and mortality associated with premature delivery. The earlier the gestation at delivery, the greater the risk to the baby of developing complications (lacovidou 2010). Immaturity of neonatal homeostatic mechanisms predispose preterm babies to respiratory distress, hypothermia (low body temperature), hypoglycaemia (low blood sugar levels), infection and jaundice. The incidence of serious morbidities increases as gestation decreases, including chronic lung disease, necrotising enterocolitis, retinopathy of prematurity, intraventricular haemorrhage and periventricular leukomalacia, all of which can lead to death or long-term disability. In 
survivors, there is also an apparent dose response between gestation at delivery and cerebral palsy, intellectual impairment and behavioural problems.

\section{Why it is important to do this review}

Despite advances in technology for recognition of fetal compromise, considerable controversy surrounds whether a policy of immediate or deferred delivery provides the best outcome for these infants. Evidence regarding the risks and benefits of each approach is needed to direct management decisions for women with suspected fetal compromise.

\section{OB JECTIVES}

To assess the effects of immediate versus deferred delivery of preterm babies with suspected fetal compromise on neonatal, maternal and long-term outcomes.

\section{METHODS}

\section{Criteria for considering studies for this review Types of studies}

All randomised trials and quasi-randomised trials, including cluster-randomised trials and studies published in abstract form, comparing a policy of immediate delivery with deferred delivery or expectant management in preterm fetuses with suspected in utero compromise. Cross-over designs were not eligible for inclusion as they are not appropriate for studying the question addressed by this review.

\section{Types of participants}

Pregnant women at less than 36 weeks' gestation in whom there is clinical suspicion of fetal compromise as defined by trialists.

Outcomes of pregnancies with fetal compromise diagnosed after 36 weeks' gestation are the focus of another Cochrane review (Bond 2015).

We included multiple pregnancies. We intended to separate monochorionic and dichorionic twins where possible and exclude women with twin-twin transfusion syndrome. This is because interventions are available that are thought to improve outcome in twin-twin transfusion, so expectant management is less relevant. However, this information was not available.

\section{Types of interventions}

Immediate delivery or deferred delivery. Immediate delivery may be by induction of labour or caesarean section. It may or may not include time for a course of effective antenatal steroids (48 hours). Deferred delivery may be for a set period of time, until test results worsen, or expectant management (waiting for spontaneous labour).

\section{Types of outcome measures}

\section{Primary outcomes}

1. Extended perinatal mortality (intrauterine death or death in the first 28 days of life).

2. Serious neonatal morbidity (composite outcome including bronchopulmonary dysplasia (BPD), necrotising enterocolitis
(NEC), intraventricular haemorrhage (IVH), retinopathy of prematurity (ROP), hypoxic Ischaemic encephalopathy (HIE).

3. Death or disability at or after two years of age.

\section{Secondary outcomes}

Perinatal

1. Stillbirth (intrauterine death of fetus at more than 24 weeks' gestation).

2. Neonatal mortality (death of a baby born with signs of life within 28 days of birth).

3. Postneonatal mortality (death of a baby greater than 28 days up to one year of life).

\section{Fetal/neonatal}

1. Cord pH less than 7.0.

2. Apgar less than seven at five minutes.

3. Apgar less than four at five minutes.

4. Any admission to neonatal intensive care or special care facility.

5. Any resuscitation required.

6. Intubation/ventilation required.

7. Interval between randomisation and delivery.

8. Gestation less than 28 weeks at delivery.

9. Gestation less than 34 weeks at delivery.

10.Birthweight less than 10th centile.

11.Birthweight less than fifth centile.

12. Birthweight less than third centile.

13. Low birthweight (less than $2.5 \mathrm{~kg}$ ).

14.Very low birthweight (less than $1.5 \mathrm{~kg}$ ).

15. Respiratory distress syndrome (as defined by trialists).

16. Meconium aspiration (as defined by trialists).

17. Seizures (as defined by trialists).

18. Infection or sepsis (as defined by trialists).

19. Neonatal cooling performed.

20.Any HIE (grade I, II or III).

21. Moderate or severe HIE (grade II or grade III).

22.IVH or germinal matrix haemorrhage.

23.BPD.

24.NEC (as defined by trialists).

25. ROP requiring treatment.

26. Periventricular leucomalacia (PVL) or ventriculomegaly.

27.Length of hospital stay.

\section{Maternal}

1. Caesarean section.

2. Induction of labour.

3. Spontaneous vaginal birth.

4. Operative vaginal birth.

5. Breastfeeding.

6. Maternal satisfaction with care.

7. Antenatal admission (days).

8. Any antenatal complication (pre-eclampsia, thromboembolic disease, antepartum haemorrhage, infection, other).

9. Administration of antenatal corticosteroids. 


\section{Long-term outcomes}

1. Neurodevelopmental impairment at or after two years of age.

2. Cerebral palsy at or after two years of age.

\section{Non pre-specified outcomes}

We also reported the following additional outcomes that we considered to be important. These were not pre-specified in our protocol.

1. Death at or after two years of age.

2. Kaufman-Assessment Battery for Children Mental Processing Component Score in childhood.

3. Death or severe disability in childhood.

4. Ventilation for more than 24 hours.

\section{Search methods for identification of studies}

The following methods section of this review is based on a standard template used by the Cochrane Pregnancy and Childbirth Group.

\section{Electronic searches}

We searched the Cochrane Pregnancy and Childbirth Group's Trials Register by contacting the Information Specialist (30 April 2016).

The Register is a database containing over 21,000 reports of controlled trials in the field of pregnancy and childbirth. For full search methods used to populate the Pregnancy and Childbirth Group's Trials Register including the detailed search strategies for CENTRAL, MEDLINE, Embase and CINAHL; the list of handsearched journals and conference proceedings, and the list of journals reviewed via the current awareness service, please follow this link to the editorial information about the Cochrane Pregnancy and Childbirth Group in the Cochrane Library and select the 'Specialized Register' section from the options on the left side of the screen.

Briefly, the Cochrane Pregnancy and Childbirth Group's Trials Register is maintained by their Information Specialist and contains trials identified from:

1. monthly searches of the Cochrane Central Register of Controlled Trials (CENTRAL);

2. weekly searches of MEDLINE (Ovid);

3. weekly searches of Embase (Ovid);

4. monthly searches of CINAHL (EBSCO);

5. handsearches of 30 journals and the proceedings of major conferences;

6. weekly current awareness alerts for a further 44 journals plus monthly BioMed Central email alerts.

Search results are screened by two people and the full text of all relevant trial reports identified through the searching activities described above is reviewed. Based on the intervention described, each trial report is assigned a number that corresponds to a specific Pregnancy and Childbirth Group review topic (or topics), and is then added to the Register. The Information Specialist searches the Register for each review using this topic number rather than keywords. This results in a more specific search set which has been fully accounted for in the relevant review sections (Included studies; Excluded studies).

\section{Searching other resources}

We searched the reference lists of retrieved studies.

We did not apply any language or date restrictions.

\section{Data collection and analysis}

The following methods section of this review is based on a standard template used by Cochrane Pregnancy and Childbirth.

\section{Selection of studies}

Two review authors independently assessed for inclusion all the potential studies identified as a result of the search strategy. We resolved any disagreement through discussion or, if required, we consulted the third review author.

\section{Data extraction and management}

We designed a form to extract data. For eligible studies, two review authors extracted the data using the agreed form. We resolved discrepancies through discussion or, if required, we consulted the third review author. Data were entered into Review Manager software (RevMan 2014) and checked for accuracy.

If information regarding any of the above had been unclear, we planned to contact authors of the original reports to provide further details.

\section{Assessment of risk of bias in included studies}

Two review authors independently assessed risk of bias for each study using the criteria outlined in the Cochrane Handbook for Systematic Reviews of Interventions (Higgins 2011). Any disagreement was resolved by discussion or by involving a third assessor.

\section{(1) Random sequence generation (checking for possible selection bias)}

We described for the one included study the method used to generate the allocation sequence in sufficient detail to allow an assessment of whether it should produce comparable groups.

We assessed the method as:

- low risk of bias (any truly random process, e.g. random number table; computer random number generator);

- high risk of bias (any non-random process, e.g. odd or even date of birth; hospital or clinic record number);

- unclear risk of bias.

\section{(2) Allocation concealment (checking for possible selection bias)}

We described the method used to conceal allocation to interventions prior to assignment and assessed whether intervention allocation could have been foreseen in advance of, or during recruitment, or changed after assignment.

We assessed the methods as:

- low risk of bias (e.g. telephone or central randomisation; consecutively numbered sealed opaque envelopes);

- high risk of bias (open random allocation; unsealed or nonopaque envelopes, alternation; date of birth);

- unclear risk of bias. 
(3.1) Blinding of participants and personnel (checking for possible performance bias)

We described the methods used, if any, to blind study participants and personnel from knowledge of which intervention a participant received. We considered that studies were at low risk of bias if they were blinded, or if we judged that the lack of blinding unlikely to affect results. We assessed blinding separately for different outcomes or classes of outcomes.

We assessed the methods as:

- low, high or unclear risk of bias for participants;

- low, high or unclear risk of bias for personnel.

\section{(3.2) Blinding of outcome assessment (checking for possible detection bias)}

We described the methods used, if any, to blind outcome assessors from knowledge of which intervention a participant received. We assessed blinding separately for different outcomes or classes of outcomes.

We assessed the methods used to blind outcome assessment as:

- low, high or unclear risk of bias.

(4) Incomplete outcome data (checking for possible attrition bias due to the amount, nature and handling of incomplete outcome data)

We described for the one included study, and for each outcome or class of outcomes, the completeness of data including attrition and exclusions from the analysis. We stated whether attrition and exclusions were reported and the numbers included in the analysis at each stage (compared with the total randomised participants), reasons for attrition or exclusion where reported, and whether missing data were balanced across groups or were related to outcomes. Where sufficient information was reported, or could be supplied by the trial authors, we planned to re-include missing data in the analyses which we undertook.

We assessed the methods as:

- low risk of bias (e.g. no missing outcome data; missing outcome data balanced across groups);

- high risk of bias (e.g. numbers or reasons for missing data imbalanced across groups; 'as treated' analysis done with substantial departure of intervention received from that assigned at randomisation);

- unclear risk of bias.

\section{(5) Selective reporting (checking for reporting bias)}

We described how we investigated the possibility of selective outcome reporting bias and what we found.

We assessed the methods as:

- low risk of bias (where it is clear that all of the study's prespecified outcomes and all expected outcomes of interest to the review have been reported);

- high risk of bias (where not all the study's pre-specified outcomes have been reported; one or more reported primary outcomes were not pre-specified; outcomes of interest are reported incompletely and so cannot be used; study fails to include results of a key outcome that would have been expected to have been reported);

- unclear risk of bias.

(6) Other bias (checking for bias due to problems not covered by (1) to (5) above)

We described any important concerns we had about other possible sources of bias.

\section{(7) Overall risk of bias}

We made explicit judgements about whether the included study was at high risk of bias, according to the criteria given in the Handbook (Higgins 2011). With reference to (1) to (6) above, we planned to assess the likely magnitude and direction of the bias and whether we considered it is likely to impact on the findings. In future updates, we will explore the impact of the level of bias through undertaking sensitivity analyses - see Sensitivity analysis.

\section{Assessment of the quality of the evidence using the GRADE approach}

For this update, we assessed the quality of the evidence using the GRADE approach as outlined in the GRADE Handbook in order to assess the quality of the body of evidence relating to the following outcomes for the main comparison.

1. Extended perinatal mortality (intrauterine death or death in the first 28 days of life).

2. Serious neonatal morbidity (composite outcome including BPD, NEC, IVH, ROP, HIE).

3. Death or disability at or after two years of age.

4. Caesarean section.

5. Infant admission to neonatal intensive care or special care facility.

6. Respiratory distress syndrome (as defined by trialists).

We used the GRADEpro Guideline Development Tool to import data from Review Manager 5.3 (RevMan 2014) in order to create a 'Summary of findings' table. A summary of the intervention effect and a measure of quality for each of the above outcomes was produced using the GRADE approach. The GRADE approach uses five considerations (study limitations, consistency of effect, imprecision, indirectness and publication bias) to assess the quality of the body of evidence for each outcome. The evidence can be downgraded from 'high quality' by one level for serious (or by two levels for very serious) limitations, depending on assessments for risk of bias, indirectness of evidence, serious inconsistency, imprecision of effect estimates or potential publication bias.

\section{Measures of treatment effect}

\section{Dichotomous data}

For dichotomous data, we presented results as summary risk ratio with $95 \%$ confidence intervals.

\section{Continuous data}

We used the mean difference if outcomes were measured in the same way between trials. We planned to use the standardised mean difference to combine trials that measured the same outcome, but used different methods. 


\section{Unit of analysis issues}

\section{Cluster-randomised trials}

We planned to include cluster-randomised trials in the analyses along with individually-randomised trials. If in future updates of this review, we include cluster-randomised trials and individuallyrandomised trials, we will adjust their sample sizes using the methods described in the Handbook [Section 16.3.4] using an estimate of the intracluster correlation co-efficient (ICC) derived from the trial (if possible), from a similar trial or from a study of a similar population. If we use ICCs from other sources, we will report this and conduct sensitivity analyses to investigate the effect of variation in the ICC. If we identify both cluster-randomised trials and individually-randomised trials, we plan to synthesise the relevant information. We will consider it reasonable to combine the results from both if there is little heterogeneity between the study designs and the interaction between the effect of intervention and the choice of randomisation unit is considered to be unlikely.

We will also acknowledge heterogeneity in the randomisation unit and perform a sensitivity analysis to investigate the effects of the randomisation unit.

\section{Cross-over trials}

Cross-over designs are not appropriate for studying the question addressed by this review.

\section{Other unit of analysis issues \\ Multiple pregnancies studies}

The one trial included in this review Thornton 2004 recruited women with singleton $(n=509)$ and multiple $(n=39)$ pregnancies. The trial did not account for non-independence of data in relation to twin pregnancies. The infants are therefore treated as independent and we have noted effects of estimates of confidence intervals in the review.

\section{Dealing with missing data}

For included studies, we noted levels of attrition. In future updates, if more eligible studies are included, we will explore the impact of including studies with high levels of missing data in the overall assessment of treatment effect by using sensitivity analysis.

For all outcomes, analyses were carried out, as far as possible, on an intention-to-treat basis, i.e. we attempted to include all participants randomised to each group in the analyses. The denominator for each outcome in the included trial was the number randomised minus any participants whose outcomes were known to be missing.

\section{Assessment of heterogeneity}

We planned to assess statistical heterogeneity in each metaanalysis using the $\mathrm{Tau}^{2}, \mathrm{I}^{2}$ and $\mathrm{Chi}^{2}$ statistics. We would have regarded heterogeneity as substantial if an $\mathrm{I}^{2}$ was greater than $30 \%$ and either $\mathrm{a} \mathrm{Tau}^{2}$ was greater than zero, or there was a low $\mathrm{P}$ value (less than 0.10) in the $\mathrm{Chi}^{2}$ test for heterogeneity. If we identified substantial heterogeneity (above $30 \%$ ), we planned to explore it by pre-specified subgroup analysis.

\section{Assessment of reporting biases}

In future updates, if there are 10 or more studies in the metaanalysis, we will investigate reporting biases (such as publication bias) using funnel plots. We will assess funnel plot asymmetry visually. If asymmetry is suggested by a visual assessment, we will perform exploratory analyses to investigate it.

\section{Data synthesis}

We carried out statistical analysis using the Review Manager software (RevMan 2014). We were unable to combine data in metaanalysis as only one study was included. In future updates, we plan to use fixed-effect meta-analysis for combining data where it is reasonable to assume that studies were estimating the same underlying treatment effect: i.e. where trials were examining the same intervention, and the trials' populations and methods were judged sufficiently similar.

In future updates, if there are more included studies and if there is clinical heterogeneity sufficient to expect that the underlying treatment effects differed between trials, or if substantial statistical heterogeneity is detected, we will use random-effects metaanalysis to produce an overall summary, if an average treatment effect across trials is considered clinically meaningful. The randomeffects summary will be treated as the average range of possible treatment effects and we will discuss the clinical implications of treatment effects differing between trials. If the average treatment effect is not clinically meaningful, we will not combine trials. If we used random-effects analyses, the results will be presented as the average treatment effect with $95 \%$ confidence intervals, and the estimates of $\mathrm{Tau}^{2}$ and $\mathrm{I}^{2}$.

\section{Subgroup analysis and investigation of heterogeneity}

In future updates of this review, if we identify substantial heterogeneity, we will investigate it using subgroup analyses and sensitivity analyses. We will consider whether an overall summary is meaningful, and if it is, we will use random-effects analysis to produce it.

We had planned to carry out the following subgroup analyses.

1. Gestational age.

2. Multiple and singleton pregnancies.

3. Method of diagnosis of suspected compromise.

However the data were not reported by the subgroups of multiple and singleton pregnancies or method of diagnosis of suspected compromise. Where possible, in future updates we will carry out these subgroup analyses.

We had planned to use the following outcomes in subgroup analyses.

1. Death or disability at or after two years of age.

2. Extended perinatal mortality (intrauterine death or death in the first 28 days of life).

3. Serious neonatal morbidity (composite outcome including BPD, NEC, IVH, ROP, HIE).

However data were not reported by subgroups for the outcomes extended perinatal mortality and serious neonatal morbidity. 
Where possible, in future updates we will use these outcomes in subgroup analyses.

We will assess subgroup differences by interaction tests available within RevMan (RevMan 2014). We will report the results of subgroup analyses quoting the $\mathrm{Chi}^{2}$ statistic and $\mathrm{P}$ value, and the interaction test $I^{2}$ value.

\section{Sensitivity analysis}

In future updates of this review, we will carry out planned sensitivity analyses (if appropriate) to explore the effect of trial quality assessed by concealment of allocation, high attrition rates, or both, with poor quality studies being excluded from the analyses in order to assess whether this makes any difference to the overall result. If future updates of the review if we include cluster- and individually- randomised studies, we will carry out a sensitivity analysis to investigate the effect of the randomisation unit. If we use an intracluster correlation co-efficient (ICC) from a source other than an included cluster-randomised trial, we will conduct sensitivity analyses to investigate the effect of variation in the ICC.

\section{RES U L T S}

\section{Description of studies}

\section{Results of the search}

The search of the Pregnancy and Childbirth Group's Trials Register identified two trials (in six reports). One study has been included (Thornton 2004) and one excluded (Langenveld 2011). See Figure 1. 
Figure 1. Study flow diagram.

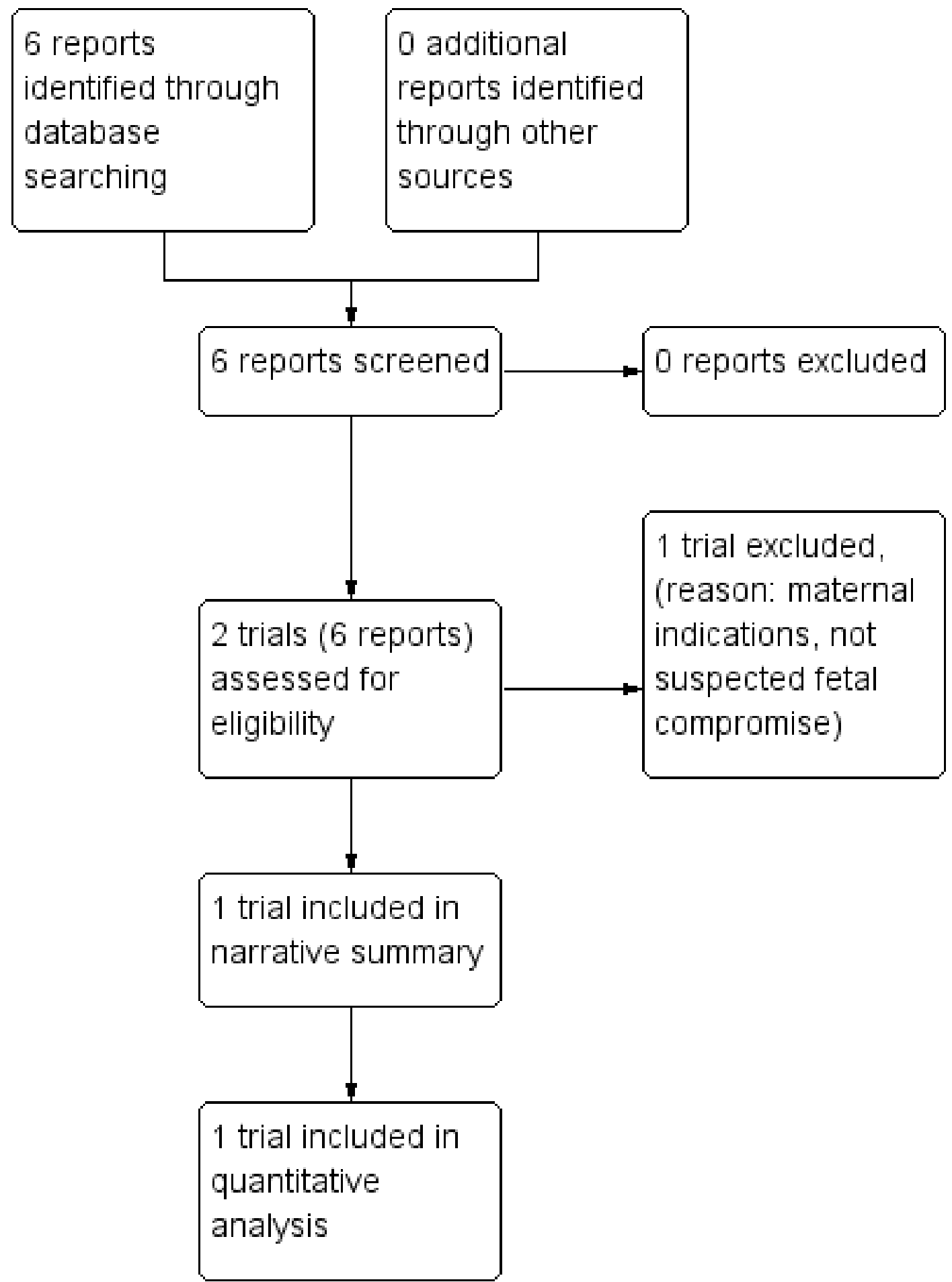

\section{Included studies}

We included one study (Thornton 2004), involving 548 women (588 babies). The Growth Restriction Intervention Study (GRIT study), led to five publications (three manuscripts GRIT 2003; Thornton 2004; Walker 2011, and two abstracts Hornbuckle 1999; Schneider 2000).
Thornton 2004, compared outcomes of immediate delivery and deferred delivery in fetuses with suspected in utero compromise. It was a multicentre randomised trial recruiting over a seven-year period (November 1993 to March 2001), with participants recruited from 69 hospitals in 13 countries (Belgium, Cyprus, Czech Republic, Germany, Greece, Hungary, Italy, Netherlands, Poland, Portugal, Saudi Arabia, Slovenia, United Kingdom). Women were included if they were 24 to 36 weeks' gestation and had a pregnancy with 
suspected fetal compromise, with the umbilical Doppler waveform recorded, and clinical uncertainty as to whether the fetus should be immediately delivered or not. Immediate delivery was defined as delivery within 48 hours to allow completion of a steroid course to promote fetal lung maturity. Deferred delivery was when worsening test results or the passage of time-favoured delivery, so safe delivery could no longer be deferred. The degree of fetal compromise was not specified, but data were collected to allow investigations of interactions between the degree of compromise and the gestation at randomisation, and outcome.

Women with both singleton $(\mathrm{n}=509)$ and multiple ( $\mathrm{n}=$ 39) pregnancies were included (588 babies). Both groups were comparable at randomisation. The primary outcome was originally "infant survival to hospital discharge and the Griffith's developmental quotient (DQ) at two years of age". However, this was changed to "death or disability at or after two years of age", which was felt to be a more precise outcome. Agreement for this change was obtained during the trial, from the data monitoring and ethics committee. Disability was defined as cerebral palsy, little or no vision, requirement for a hearing aid, or a Griffiths DQ of 70 or less. The primary outcome was reported in Thornton 2004. An earlier publication (GRIT 2003), reported early outcomes including mode of delivery, perinatal mortality and indicators of neonatal morbidity. A subsequent manuscript reported childhood outcomes (Walker 2011), including Kaufman-Assessment Battery for Children Mental Processing Component (Kaufman ABC MPC) and death or disability, at six to 13 years, in a subset of the original cohort. Two abstracts were also published (Hornbuckle 1999; Schneider 2000), but these were interim analysis and so data from these were not included in this review.

The study analysis and data monitoring were Bayesian. Odds ratios were calculated and used to revise hypothetical prior beliefs about the outcomes of immediate or deferred delivery. There were no specified stopping rules for the trial. Interim analyses of unmasked data were presented to the data monitoring committee every year and to clinical collaborators every two years. The aim of this was to allow individuals with strong prior beliefs on the value of intervention to stop recruiting if they were no longer clinically uncertain, and to encourage other clinicians to recruit if they became unsure of the benefit of delivery.

\section{Excluded studies}

The HYPITAT II trial (Langenveld 2011) completed in 2013. This study investigated immediate or deferred delivery for maternal indications (gestational hypertension, chronic hypertension or preeclampsia) rather than for suspected fetal compromise and did not therefore fulfil our inclusion criteria.

\section{Risk of bias in included studies}

See Figure 2. 
Figure 2. 'Risk of bias' summary: review authors' judgements about each risk of bias item for each included study.

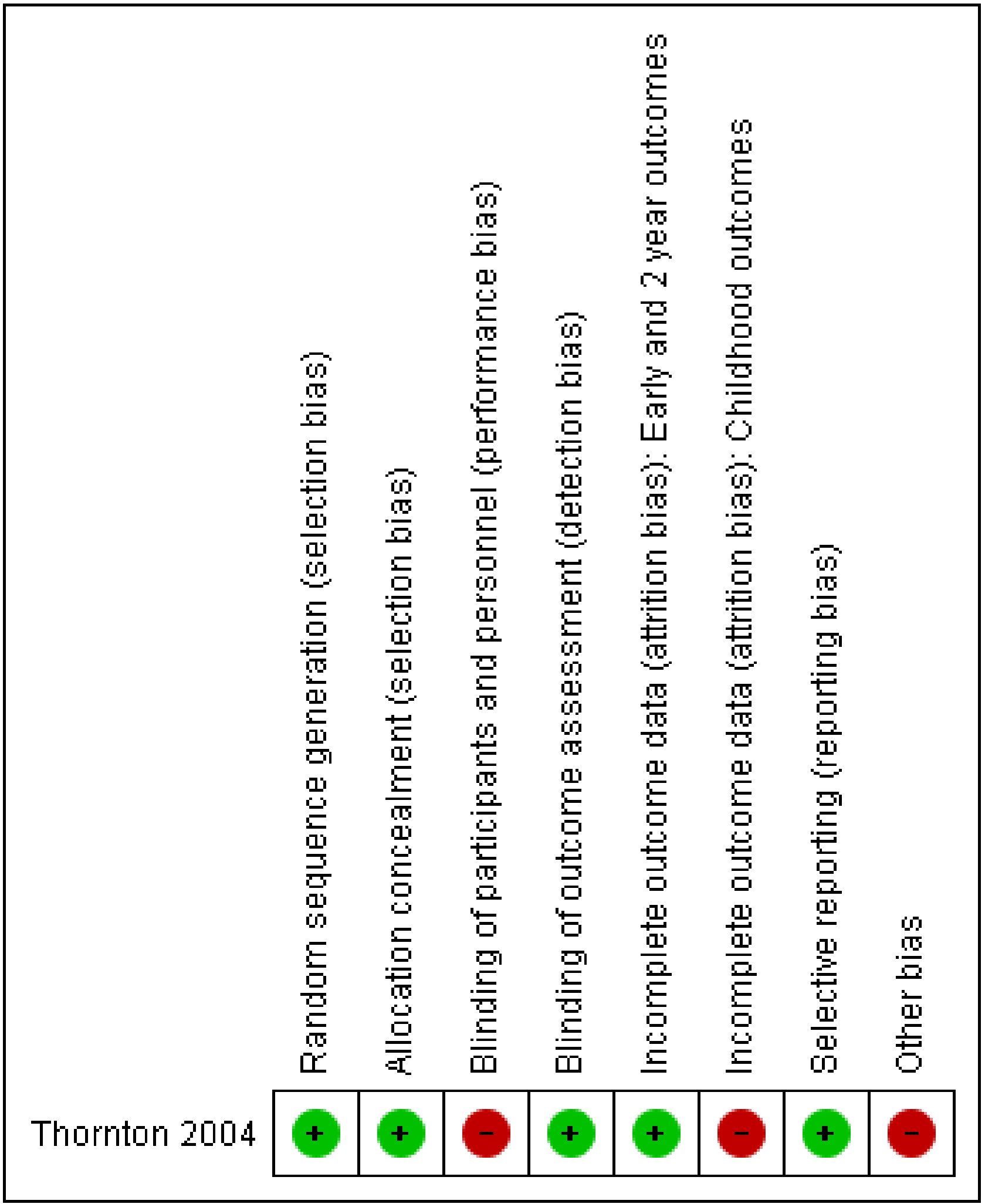

\section{Allocation}

In the included study (Thornton 2004), allocation was performed by an independent programmer. During office hours, a computergenerated sequence was used, and out of office hours, a paper- based number sequence with balanced blocks of eight to 12 was used, so allocation was masked from participating clinicians. We judged this study to be at a low risk of selection bias. 


\section{Blinding}

The nature of the intervention meant that blinding of patients or personnel was not possible (high risk of bias). Indeed, unmasked interim analysis data were presented to collaborators, as part of trial design, as analysis was planned to be Bayesian with odds ratios obtained used to revise prior beliefs about outcomes.

Assesors performing assessments at two years were blinded to randomisation group so the risk of detection bias was low for the primary outcome.

\section{Incomplete outcome data}

Two-hundred and ninety-six fetuses were randomised to immediate delivery, and 291 fetuses to deferred delivery. One woman with a singleton pregnancy randomised to deferred delivery discharged herself from hospital and was lost to follow-up. Early outcomes of all other fetuses are reported (GRIT 2003), thus for early outcomes there was less than $5 \%$ incomplete data and the risk of bias is low.

At two-year assessment, an additional six babies in the immediate delivery group and eight in the deferred group were lost to followup (Thornton 2004), thus for two-year outcomes there was less than $5 \%$ incomplete data and the risk of bias is low.

Childhood follow-up was attempted in children born to women randomised in five of the original recruiting countries (Germany, Italy, The Netherlands, Slovenia, and United Kingdom; Walker 2011). Data from Italy were not reported due to a high loss to followup rate $(75 \%)$. Follow-up data on children from other countries were available in $153 / 173$ cases in the immediate delivery group and $149 / 183$ in the deferred delivery group. As there is more than $5 \%$ incomplete data the risk of bias for childhood outcomes is high.

\section{Selective reporting}

The study protocol was published online and available for review. Outcomes and analysis strategies were pre-specified, and there is no evidence of selective reporting of outcomes (low risk of bias).

\section{Other potential sources of bias}

Multiple pregnancies were included, but no adjustment was made in the analysis to take account of non-independence between babies from the same pregnancy (Brocklehurst 2004), resulting in a high risk of bias.

\section{Effects of interventions}

See: Summary of findings for the main comparison Immediate versus deferred delivery of the preterm baby with suspected fetal compromise for improving outcomes

\section{Immediate delivery versus deferred delivery}

\section{Primary outcomes}

There was no clear difference in extended perinatal mortality (intrauterine death or death in the first $\mathbf{2 8}$ days of live) with immediate delivery compared to deferred delivery (risk ratio (RR) 1.17, 95\% confidence interval $(\mathrm{Cl}) 0.67$ to 2.04 , one trial, 587 babies (Analysis 1.1), moderate-quality evidence). There was also no clear difference in the risk of the composite outcome of death or disability at or after two years (RR $1.22,95 \% \mathrm{Cl} 0.85$ to 1.75 , one trial, 573 babies (Analysis 1.2), moderate-quality evidence).
These outcomes had wide $\mathrm{Cls}$, and the results are consistent with both appreciable benefit and harm. We were not able to calculate composite rates of serious neonatal morbidity, even though individual morbidities were reported, due to the risk of double counting infants with more than one morbidity.

\section{Subgroup analysis}

Compared to deferred delivery, the RR of death or disability at two years with immediate delivery was $1.21(95 \% \mathrm{Cl} 0.81$ to 1.80$)$ at 24 to 30 weeks (subgroup A), and $1.04(95 \% \mathrm{Cl} 0.54$ to 2.01$)$ at 31 to 36 weeks (subgroup B). No significant difference in effect was found between the subgroups $(P=0.70)$ (see Analysis 1.19).

\section{Secondary outcomes}

\section{Perinatal outcomes}

There was a trend towards decreasedstillbirth with immediate delivery (RR $0.22,95 \% \mathrm{Cl} 0.05$ to 1.00 , one trial, 587 babies (Analysis 1.3)). However, this was offset by a possible increase in neonatal mortality (RR $1.84,95 \% \mathrm{Cl} 0.93$ to 3.62 , one trial, 576 babies (Analysis 1.4)). There were no differences in post neonatal mortality (RR $0.66,95 \% \mathrm{Cl} 0.19$ to 2.33 , one trial, 541 babies (Analysis 1.5)) with immediate delivery compared to deferred delivery.

\section{Fetal/neonatal outcomes}

There were no differences between the immediate delivery and deferred delivery groups in any neonatal morbidity or marker of neonatal morbidity pre-specified in the protocol. Data were available on cord pH less than $\mathbf{7 . 0 0}(\mathrm{RR} 0.50,95 \% \mathrm{Cl} 0.09$ to 2.70 , one trial, 400 babies (Analysis 1.7)); Apgar less than seven at five minutes (RR $1.49,95 \% \mathrm{Cl} 0.82$ to 2.70 , one trial, 560 babies (Analysis 1.8)); convulsions (RR $1.44,95 \% \mathrm{Cl} 0.24$ to 8.55, one trial, 576 babies (Analysis 1.10)); intraventricular haemorrhage (IVH) orgerminal matrix haemorrhage ( $\mathrm{RR} 1.28,95 \% \mathrm{Cl} 0.84$ to 1.95 , one trial, 576 babies (Analysis 1.11)); necrotising enterocolitis (NEC) (RR $1.44,95 \% \mathrm{Cl} 0.71$ to 2.93, one trial, 576 babies (Analysis 1.12)); and periventricular leucomalacia or ventriculomegaly (RR 2.04, $95 \% \mathrm{Cl} 0.89$ to 4.65 , one trial, 576 babies (Analysis 1.13)).

The following pre-specified fetal/neonatal outcomes were not reported: Apgar less than four at five minutes, any admission to neonatal intensive care or special care facility, any resuscitation required, intubation/ventilation required, interval between randomisation and delivery, gestation less than 28 weeks at delivery, gestation less than 34 weeks at delivery, birthweight less than 10th centile, birthweight less than fifth centile, birthweight less than third centile, low birthweight (less than $2.5 \mathrm{~kg}$ ), very low birthweight (less than $1.5 \mathrm{~kg}$ ), respiratory distress syndrome (as defined by trialists), meconium aspiration (as defined by trialists), seizures (as defined by trialists), infection or sepsis (as defined by trialists), neonatal cooling performed, any hypoxic Ischaemic encephalopathy (HIE) (grade I, II or III), moderate or severe HIE (grade II or grade III), bronchopulmonary dysplasia (BPD), retinopathy of prematurity (ROP) requiring treatment, andlength of hospital stay.

\section{Maternal outcomes}

More women in the immediate delivery group had caesarean delivery than in the deferred delivery group (RR 1.15, 95\% Cl 1.07 to 1.24, one trial, 547 women (Analysis 1.18), high-quality evidence). 
Data were not available on any other pre-specified maternal outcomes (induction of labour, spontaneous vaginal birth, operative vaginal birth, breastfeeding, maternal satisfaction with care, antenatal admission (days), any antenatal complication (pre-eclampsia, thromboembolic disease, antepartum haemorrhage, infection, other), andadministration of antenatal corticosteroids).

\section{Long-term outcomes}

More children in the immediate delivery group had cerebral palsy at or after two years of age ( $\mathrm{RR} 5.88,95 \% \mathrm{Cl} 1.33$ to 26.02 , one trial, 507 children (Analysis 1.15)). There was, however, no clear difference in neurodevelopment impairment at or after two years (RR 1.72, 95\% Cl 0.86 to 3.41, one trial, 507 children (Analysis 1.14)).

\section{Non pre-specified outcomes}

More babies in the immediate delivery group were ventilated for more than 24 hours (RR $1.54,95 \% \mathrm{Cl} 1.20$ to 1.97 , one trial, 576 babies (Analysis 1.9)). There were no differences between the immediate delivery and deferred delivery groups in death at or after two years (RR 1.04, 95\% Cl 0.66 to 1.63, one trial, 573 children (Analysis 1.6)); death or disability in childhood (six to 13 years of age) (RR $0.82,95 \% \mathrm{Cl} 0.48$ to 1.40 , one trial, 302 children (Analysis 1.16)); or mean difference (MD) in childhood Kaufman-ABC MPC Score (MD $-1.00,95 \% \mathrm{Cl}-4.47$ to 2.47 , one trial, 269 children (Analysis 1.17)).

\section{DISCUSSION}

\section{Summary of main results}

We identified one study (Thornton 2004, involving 548 women (588 babies)) examining whether immediate or deferred delivery improved outcomes when there is suspected fetal compromise in the preterm fetus. This study only included cases of suspected fetal compromise where there was uncertainty whether immediate delivery was indicated, thus results must be interpreted with caution.

The difference in the median randomisation to delivery interval between immediate delivery and deferred delivery was four days (median: 0.9 (inter-quartile range (IQR) 0.4 to 1.3 ) days for immediate delivery, median: 4.9 (IQR 2.0 to 10.8 ) days in the delay group). The available data showed immediate delivery results in higher rates of caesarean delivery than deferred delivery. Although no clear differences were evident in perinatal mortality, or a composite measure of death or disability at or after two years, immediate delivery resulted in more neonatal ventilation and greater incidence of cerebral palsy at or after two years of age. Childhood outcomes were also reported, and although it must be noted that follow-up data were incomplete, no differences in outcome were found between immediate and deferred delivery groups.

Together these findings suggest that where there is uncertainty whether or not to deliver a preterm fetus with suspected fetal compromise, there is no benefit to immediate delivery. Deferring delivery until test results worsen or increasing gestation favours delivery, may improve outcomes for mother and neonate.

\section{Overall completeness and applicability of evidence}

There is a lack of trials in this area, and only one study was identified. Although it is a relatively large study, it has insufficient power to detect differences in neonatal mortality. It did not report any maternal outcomes, other than mode of delivery, or evaluate maternal satisfaction or economic outcomes.

The applicability of the findings is limited by several factors. Firstly, the broad inclusion criteria of the included trial, which recruited women with a range of different Doppler findings and obstetric complications, as well as different gestational ages. Numbers were insufficient to allow meaningful assessment of the impact of the severity of Doppler abnormality or the presence of obstetric conditions (for example, maternal hypertension or vaginal bleeding) on outcomes. The potential benefits of immediate delivery are likely to change with gestation. Post hoc subgroup analysis did not detect any significant difference in the effect of immediate or deferred delivery at early ( 24 to 30 weeks) or later (31 to 36 weeks) gestations.

Secondly, the study only included cases where the responsible clinician was uncertain whether to deliver or not. The authors were unable to report how many eligible women were offered participation, how many declined randomisation or how many potential participants were not included because of clinician certainty regarding timing for delivery. Thus, the proportion of pregnant women with suspected fetal compromise included in the study, and the generalisability of the findings, are unclear.

Thirdly, the difference in the median time between randomisation and delivery in the two groups was four days. The potential benefits of deferring delivery for longer or shorter periods cannot be presumed.

Finally, the study did not evaluate the use of more recently developed Doppler assessment techniques such as ductus venosus or middle cerebral artery waveforms which may diagnose more accurately severe compromise and help make decisions about the timing of delivery (Alfirevic 2013).

\section{Quality of the evidence}

We identified a single large multicentre study, performed in 13 countries. There were several methodological weaknesses in the included study: The nature of the intervention meant that participants could not be blinded to their treatment group. However, the assessors were blinded to allocation at two-year assessment. There was incomplete follow-up data for childhood outcomes, placing these outcomes at high risk of attrition bias. No adjustment was made in the analysis for the non-independence of babies from multiple pregnancies (39 out of 548 pregnancies).

We used the GRADE approach to assess the quality of the evidence. The level of evidence for the primary outcomes (extended perinatal mortality and death or disability at or after two years) was graded moderate. The evidence was downgraded for imprecision, because the confidence interval crossed the line of no effect and appreciable benefit. The level of evidence for caesarean section was graded high. Two outcomes selected for the 'Summary of findings' table were not reported: infant admission to neonatal intensive care or special care facility, and respiratory distress syndrome. We were not able to calculate composite rates of serious neonatal morbidity, even though individual morbidities were reported, due to the risk 
of double counting infants with more than one morbidity. See Summary of findings for the main comparison.

The design and analysis of the included study was Bayesian. This differs from conventional methodology, where differences in outcome are assessed with $\mathrm{P}$ values. Instead odds ratios were presented with credibility indices (similar to confidence intervals, representing the range in which the true value is likely to lie), and these were used to revise hypothetical prior beliefs that clinicians may have had regarding the benefits of immediate or deferred delivery. A purported advantage of this design is to allow assessment of the impact that the trial findings will have on clinical practice. Integral to the design is the presentation of unmasked data to collaborators as well as the data monitoring committee, in order to allow collaborators to modify their beliefs on the benefit or harm of the intervention. Although this differs from traditional methodology where interim analysis and findings are masked, we do not believe it was an important bias.

The lack of other studies and limited applicability of the findings mean caution must be used in the interpretation of the findings.

\section{Potential biases in the review process}

We specified broad inclusion criteria for this review, so we could use all the available evidence. However, only one study was identified despite a rigorous literature search, meaning analysis was limited.

\section{Agreements and disagreements with other studies or reviews}

We are not aware of any other studies or reviews investigating this question. However the Truffle (Trial of umbilical and fetal flow in Europe) trial (Lees 2015), investigated which method of fetal assessment should be used as an indication for delivery in mothers with very preterm fetuses ( $<32$ weeks' gestation) with suspected compromise due to growth restriction-early or late changes in the fetal ductus venosus Doppler waveform or CTG short-term variation. There was no difference in the primary outcome of the trial, which was the proportion of children free from neuroimpairment at two years old (defined as cerebral palsy, neurosensory impairment, or a Bayley III developmental score of less than 85). Nevertheless, the findings suggested that waiting for late ductus venosus changes (or severe CTG changes, which were used as safety net indication for delivery) did not significantly increase hypoxia-related deaths and was associated with more favourable developmental outcomes at two years for babies with early onset fetal growth restriction. This would support our conclusion that expectant management may improve neonatal outcomes.

\section{AUTHORS' CONCLUSIONS}

\section{Implications for practice}

Currently there is insufficient evidence on the benefits and harms of immediate delivery compared with deferred delivery in cases of suspected fetal compromise at preterm gestations to guide clinical practice. However, immediate delivery appears to increase caesarean delivery and does not improve neonatal outcome. When there is uncertainty regarding the optimal time for delivery of the preterm fetus with suspected fetal compromise, deferring delivery until test results worsen or increasing gestation favours delivery, may improve outcomes for mother and neonate.

\section{Implications for research}

Further randomised trials are required comparing immediate and deferred delivery where there is suspected fetal compromise at preterm gestations to guide clinical practice. These should be adequately powered to detect differences in maternal and neonatal morbidity and mortality. Such studies should include all important outcomes, including economic evaluation and investigation of maternal preferences.

\section{ACKNOWLEDGEMENTS}

Sarah Stock and Jane Norman work in the Tommy's Centre for Maternal and Fetal Health, Edinburgh. Tommy's provided infrastructure costs, funding for Sarah Stock to attend Cochrane training courses, and expenses for meetings.

Denise Atherton for administrative assistance; Lynn Hampson for the literature search.

Helen West's work is supported by the NIHR Cochrane Programme Grant Project: 13/89/05 - Pregnancy and childbirth systematic reviews to support clinical guidelines.

This project was supported by the National Institute for Health Research, via Cochrane Infrastructure and Cochrane Programme Grant funding to Cochrane Pregnancy and Childbirth. The views and opinions expressed therein are those of the authors and do not necessarily reflect those of the Systematic Reviews Programme, NIHR, NHS or the Department of Health. 


\section{R E F E R E N C E S}

\section{References to studies included in this review}

Thornton 2004 \{published data only\}

GRIT Study Group. A randomised trial of timed delivery for the compromised preterm fetus: short term outcomes and bayesian interpretation. BJOG: an international journal of obstetrics and gynaecology 2003;110:27-32.

Hornbuckle J, Thornton JG, Vail A, GRIT Study Group. The Growth Restriction Intervention Trial (GRIT): interim progress report. Women's Health - into the new millennium. Proceedings of the 4th International Scientific Meeting of the Royal College of Obstetricians and Gynaecologists; 1999 October 3-6; Cape Town South Africa. RCOG, 1999:76.

Schneider KTM, Brocker J, Thornton J. A randomised intervention of timed delivery for the compromised preterm fetus [Randomisierte Intervention zur Optimierung des Entbindungszeitpunktes bei kompromittierten IUGR-Feten (Euro-GRIT)]. Geburtshilfe und Frauenheilkunde 2000;60 Suppl 1:S72.

* Thornton JG, Hornbuckle J, Vail A, Spiegelhalter DJ, Levene M, GRIT study group. Infant wellbeing at 2 years of age in the Growth Restriction Intervention Trial (GRIT): multicentred randomised controlled trial. Lancet 2004;364:513-20.

Walker DM, Marlow N, Upstone L, Gross H, Hornbuckle J, Vail A, et al. The growth restriction intervention trial: Longterm outcomes in a randomized trial of timing of delivery in fetal growth restriction. American Journal of Obstetrics and Gynecology 2011;204(1):34.e1-34.e9.

\section{References to studies excluded from this review}

\section{Langenveld 2011 \{published data only\}}

Langenveld J, Broekhuijsen K, Van Baaren GJ, Van Pampus MG, Van Kaam AH, Groen H, et al. HYPITAT-II study group. Induction of labour versus expectant monitoring for gestational hypertension or mild pre-eclampsia between 34 and 37 weeks' gestation (HYPITAT-II): a multicentre, open-label randomised controlled trial. BMC Pregnancy Childbirth 2011;11:50-7. [PUBMED: 21736705]

\section{Additional references}

\section{Alberry 2007}

Alberry M, Soothill P. Management of fetal growth restriction. Archives of Disease in Childhood. Fetal and Neonatal Edition 2007;92(1):F62-F67. [PUBMED: 17185432]

\section{Alfirevic 2013}

Alfirevic Z, Stampalija T, Gyte GML. Fetal and umbilical Doppler ultrasound in high-risk pregnancies. Cochrane Database of Systematic Reviews 2013, Issue 11. [DOI: 10.1002/14651858.CD007529.pub3]

\section{Bond 2015}

Bond DM, Gordon A, Hyett J, de Vries B, Carberry AE, Morris J. Planned early delivery versus expectant management of the term suspected compromised baby for improving outcomes. Cochrane Database of Systematic Reviews 2015, Issue 11. [DOI: 10.1002/14651858.CD009433.pub2]

\section{Bricker 2009}

Bricker L, Mahsud-Dornan S, Dornan JC. Detection of foetal growth restriction using third trimester ultrasound. Best Practice \& Research. Clinical Obstetrics \& Gynaecology 2009;23(6):833-44. [PUBMED: 19811955]

\section{Brocklehurst 2004}

Gates S, Brocklehurst P. How should randomised trials including multiple pregnancies be analysed?. BJOG: an international journal of obstetrics and gynaecology 2004;111(3):213-9.

\section{GRIT 2003}

GRIT Study Group. A randomised trial of timed delivery for the compromised preterm fetus: short term outcomes and bayesian interpretation. BJOG: an international journal of obstetrics and gynaecology 2003;110:27-32.

\section{Grivell 2012}

Grivell RM, Wong L, Bhatia V. Regimens of fetal surveillance for impaired fetal growth. Cochrane Database of Systematic Reviews 2012, Issue 6. [DOI: 10.1002/14651858.CD007113.pub3]

\section{Grivell 2015}

Grivell RM, Alfirevic Z, Gyte GML, Devane D. Antenatal cardiotocography for fetal assessment. Cochrane Database of Systematic Reviews 2015, Issue 9. [DOI: 10.1002/14651858.CD007863.pub4]

\section{Guzman 1996}

Guzman ER, Vintzileos AM, Martins M, Benito C, Houlihan C, Hanley M. The efficacy of individual computer heart rate indices in detecting acidemia at birth in growth-restricted fetuses. Obstetrics \& Gynecology 1996;87(6):969-74.

\section{Higgins 2011}

Higgins JPT, Green S, editors. Cochrane Handbook for Systematic Reviews of Interventions Version 5.1.0 [updated March 2011]. The Cochrane Collaboration, 2011. Available from www.cochrane-handbook.org.

\section{Hofmeyr 2012}

Hofmeyr G. Abdominal decompression for suspected fetal compromise/pre-eclampsia. Cochrane Database of Systematic Reviews 2012, Issue 6. [DOI: 10.1002/14651858.CD000004.pub2]

\section{Hornbuckle 1999}

Hornbuckle J, Thornton JG, Vail A, GRIT Study Group. The Growth Restriction Intervention Trial (GRIT): interim progress report. Women's Health - into the new millennium. Proceedings of the 4th International Scientific Meeting of the Royal College of Obstetricians and Gynaecologists; 1999 October 3-6; Cape Town South Africa. RCOG, 1999:76. 


\section{lacovidou 2010}

lacovidou N, Varsami M, Syggellou A. Neonatal outcome of preterm delivery. Annals of the New York Academy of Sciences 2010;1205:130-4.

\section{Lalor 2008}

Lalor JG, Fawole B, Alfirevic Z, Devane D. Biophysical profile for fetal assessment in high risk pregnancies. Cochrane Database of Systematic Reviews 2008, Issue 1. [DOI: 10.1002/14651858.CD000038.pub2]

\section{Lees 2015}

Lees CC, Marlow N, van Wassenaer-Leemhuis A, Arabin B, Bilardo CM, Brezinka C, et al. 2 year neurodevelopmental and intermediate perinatal outcomes in infants with very preterm fetal growth restriction (TRUFFLE): a randomised trial. Lancet 2015;385(9983):2162-72. [DOI: 10.1016/S0140-6736(14)62049-3]

\section{Miller 2008}

Miller J, Turan S, Baschat AA. Fetal growth restriction. Seminars in Perinatology 2008;32(4):274-80. [PUBMED: 18652928]

\section{Nabhan 2008}

Nabhan AF, Abdelmoula YA. Amniotic fluid index versus single deepest vertical pocket as a screening test for preventing adverse pregnancy outcome. Cochrane Database of Systematic Reviews 2008, Issue 3. [DOI: 10.1002/14651858.CD006593.pub2]

\section{RevMan 2014 [Computer program]}

The Nordic Cochrane Centre, The Cochrane Collaboration. Review Manager (RevMan). Version 5.3. Copenhagen: The Nordic Cochrane Centre, The Cochrane Collaboration, 2014.

\section{Roberts 2014}

Roberts D, Neilson JP, Kilby M, Gates S. Interventions for the treatment of twin-twin transfusion syndrome. Cochrane Database of Systematic Reviews 2014, Issue 1. [DOI: 10.1002/14651858.CD002073.pub3]

\section{Say 1996a}

Say L, Gülmezoglu AM, Hofmeyr GJ. Bed rest in hospital for suspected impaired fetal growth. Cochrane Database of Systematic Reviews 1996, Issue 1. [DOI: 10.1002/14651858.CD000034]

\section{Say 1996b}

Say L, Gulmezoglu AM, Hofmeyr GJ. Transcutaneous electrostimulation for suspected placental insufficiency (diagnosed by Doppler studies). Cochrane Database of Systematic Reviews 1996, Issue 1. [DOI: 10.1002/14651858.CD000079]

\section{Say 1996c}

Say L, Gülmezoglu AM, Hofmeyr GJ. Calcium channel blockers for potential impaired fetal growth. Cochrane
Database of Systematic Reviews 1996, Issue 1. [DOI: 10.1002/14651858.CD000049]

\section{Say 1996d}

Say L, Gülmezoglu AM, Hofmeyr GJ. Plasma volume expansion for suspected impaired fetal growth. Cochrane Database of Systematic Reviews 1996, Issue 4. [DOI: 10.1002/14651858.CD000167]

\section{Say 2001}

Say L, Gülmezoglu AM, Hofmeyr GJ. Betamimetics for suspected impaired fetal growth. Cochrane Database of Systematic Reviews 2001, Issue 4. [DOI: 10.1002/14651858.CD000036]

\section{Say 2003a}

Say L, Gulmezoglu AM, Hofmeyr GJ. Maternal oxygen administration for suspected impaired fetal growth. Cochrane Database of Systematic Reviews 2003, Issue 1. [DOI: 10.1002/14651858.CD000137]

\section{Say 2003b}

Say L, Gulmezoglu AM, Hofmeyr GJ. Hormones for suspected impaired fetal growth. Cochrane Database of Systematic Reviews 2003, Issue 1. [DOI: 10.1002/14651858.CD000109]

\section{Say 2003c}

Say L, Gulmezoglu AM, Hofmeyr GJ. Maternal nutrient supplementation for suspected impaired fetal growth. Cochrane Database of Systematic Reviews 2003, Issue 1. [DOI: 10.1002/14651858.CD000148]

\section{Schneider 2000}

Schneider KTM, Brocker J, Thornton J. A randomised intervention of timed delivery for the compromised preterm fetus [Randomisierte Intervention zur Optimierung des Entbindungszeitpunktes bei kompromittierten IUGR-Feten (Euro-GRIT)]. Geburtshilfe und Frauenheilkunde 2000;60 Suppl 1:S72.

\section{Walker 2011}

Walker DM, Marlow N, Upstone L, Gross H, Hornbuckle J, Vail A, et al. The growth restriction intervention trial: Longterm outcomes in a randomized trial of timing of delivery in fetal growth restriction. American Journal of Obstetrics and Gynecology 2011;204(1):34.e1-34.e9.

\section{References to other published versions of this review Stock 2012}

Stock SJ, Bricker L, Norman JE. Immediate versus deferred delivery of the preterm baby with suspected fetal compromise for improving outcomes. Cochrane Database of Systematic Reviews 2012, Issue 7. [DOI: 10.1002/14651858.CD008968.pub2]

* Indicates the major publication for the study 
CHARACTERISTICS OF STUDIES

Characteristics of included studies [ordered by study ID]

Thornton 2004

\begin{tabular}{ll}
\hline Methods & Multicentre randomised controlled trial. \\
\hline Participants & $\begin{array}{l}548 \text { women (singleton } 509, \text { multiple 39) } 588 \text { babies, } 24-36 \text { weeks' gestation with umbilical artery } \\
\text { Doppler recorded and uncertainty whether to deliver or not. } \\
\text { Outcomes available at or after } 2 \text { years for } 575 \text { babies. }\end{array}$ \\
\hline Interventions & $\begin{array}{l}\text { Immediate delivery (allowing } 48 \text { hours for completion of steroids) OR deferred delivery (when safe de- } \\
\text { livery could be delayed no longer, because worsening test results or the passage of time-favoured deliv- } \\
\text { ery). }\end{array}$ \\
\hline Death or disability (cerebral palsy, little or no vision, requirement for a hearing aid, or a Griffiths DQ of \\
70 or less), at or after 2 years of age. \\
$\begin{array}{l}\text { The design and analysis of the included study was Bayesian. Odds ratios were presented with credibil- } \\
\text { ity indices (similar to confidence intervals, representing the range in which the true value is likely to } \\
\text { lie), and these were used to revise hypothetical prior beliefs that clinicians may have had regarding the } \\
\text { benefits of immediate or deferred delivery. }\end{array}$
\end{tabular}

Notes Primary outcome of GRIT trial.

\section{Risk of bias}

\begin{tabular}{lll}
\hline Bias & Authors' judgement & Support for judgement \\
\hline $\begin{array}{l}\text { Random sequence genera- } \\
\text { tion (selection bias) }\end{array}$ & Low risk & Computer-generated random sequence. \\
\hline $\begin{array}{l}\text { Allocation concealment } \\
\text { (selection bias) }\end{array}$ & Low risk & Allocation by an independent programmer. \\
\hline
\end{tabular}

\begin{tabular}{lll}
\hline $\begin{array}{l}\text { Blinding of participants } \\
\text { and personnel (perfor- } \\
\text { mance bias) } \\
\text { All outcomes }\end{array}$ & High risk & Not blinded due to nature of intervention. \\
\hline $\begin{array}{l}\text { Blinding of outcome as- } \\
\text { sessment (detection bias) } \\
\text { All outcomes }\end{array}$ & Low risk & $\begin{array}{l}\text { Assessors blinded to allocation at 2-year follow-up. It is unclear whether asses- } \\
\text { sors were blinded to allocation at childhood follow-up, therefore unclear risk } \\
\text { of bias for these outcomes. }\end{array}$ \\
\hline
\end{tabular}

\begin{tabular}{lll}
\hline $\begin{array}{l}\text { Incomplete outcome data } \\
\text { (attrition bias) } \\
\text { Early and 2 year outcomes }\end{array}$ & Low risk & Less than 5\% incomplete data for early and 2-year outcomes. \\
\hline $\begin{array}{l}\text { Incomplete outcome data } \\
\text { (attrition bias) } \\
\text { Childhood outcomes }\end{array}$ & High risk & $\begin{array}{l}\text { More than } 5 \% \text { missing data for childhood outcomes, therefore high risk of bias } \\
\text { for these outcomes. }\end{array}$ \\
\hline $\begin{array}{l}\text { Selective reporting (re- } \\
\text { porting bias) }\end{array}$ & Low risk & Protocol published and no suggestion of selective reporting of outcomes. \\
\hline $\begin{array}{l}\text { Other bias } \\
\text { High risk }\end{array}$ & $\begin{array}{l}\text { Trial did not account for non-independence of data in relation to twin preg- } \\
\text { nancies. }\end{array}$ \\
\hline
\end{tabular}


Characteristics of excluded studies [ordered by study ID]

\begin{tabular}{ll}
\hline Study & Reason for exclusion \\
\hline Langenveld 2011 & $\begin{array}{l}\text { Protocol for a trial investigating immediate or deferred delivery for maternal indications (gesta- } \\
\text { tional hypertension, chronic hypertension or pre-eclampsia) rather than for suspected fetal com- } \\
\text { promise and did not therefore fulfil our inclusion criteria. [The trial completed in 2013.] }\end{array}$ \\
\hline
\end{tabular}

DATA AND ANALYSES

Comparison 1. Immediate delivery versus deferred delivery

\begin{tabular}{|c|c|c|c|c|}
\hline Outcome or subgroup title & No. of studies & $\begin{array}{l}\text { No. of partici- } \\
\text { pants }\end{array}$ & Statistical method & Effect size \\
\hline 1 Extended perinatal mortality & 1 & 587 & Risk Ratio (M-H, Fixed, 95\% Cl) & $1.17[0.67,2.04]$ \\
\hline $\begin{array}{l}2 \text { Death or disability at or after } 2 \\
\text { years }\end{array}$ & 1 & 573 & Risk Ratio (M-H, Fixed, 95\% Cl) & $1.22[0.85,1.75]$ \\
\hline 3 Stillbirth & 1 & 587 & Risk Ratio (M-H, Fixed, 95\% Cl) & $0.22[0.05,1.00]$ \\
\hline 4 Neonatal mortality & 1 & 576 & Risk Ratio (M-H, Fixed, 95\% Cl) & $1.84[0.93,3.62]$ \\
\hline $\begin{array}{l}5 \text { Postneonatal mortality ( }>28 \\
\text { days to discharge) }\end{array}$ & 1 & 541 & Risk Ratio (M-H, Fixed, 95\% Cl) & $0.66[0.19,2.33]$ \\
\hline 6 Death at or after 2 years of age & 1 & 573 & Risk Ratio (M-H, Fixed, 95\% Cl) & $1.04[0.66,1.63]$ \\
\hline 7 Cord pH less than 7.0 & 1 & 400 & Risk Ratio (M-H, Fixed, 95\% Cl) & $0.5[0.09,2.70]$ \\
\hline 8 Apgar less than 7 at 5 minutes & 1 & 560 & Risk Ratio (M-H, Fixed, 95\% Cl) & $1.49[0.82,2.70]$ \\
\hline 9 Ventilation $>24$ hours & 1 & 576 & Risk Ratio (M-H, Fixed, 95\% Cl) & $1.54[1.20,1.97]$ \\
\hline 10 Convulsions & 1 & 576 & Risk Ratio (M-H, Fixed, 95\% Cl) & $1.44[0.24,8.55]$ \\
\hline $\begin{array}{l}11 \text { Interventricular haemorrhage } \\
\text { or germinal matrix haemorrhage }\end{array}$ & 1 & 576 & Risk Ratio (M-H, Fixed, 95\% Cl) & $1.28[0.84,1.95]$ \\
\hline 12 Necrotising enterocolitis & 1 & 576 & Risk Ratio (M-H, Fixed, 95\% Cl) & $1.44[0.71,2.93]$ \\
\hline $\begin{array}{l}13 \text { Periventricular leucomalacia or } \\
\text { ventriculomegaly }\end{array}$ & 1 & 576 & Risk Ratio (M-H, Fixed, 95\% Cl) & $2.04[0.89,4.65]$ \\
\hline $\begin{array}{l}14 \text { Neurodevelopmental impair- } \\
\text { ment at or after } 2 \text { years }\end{array}$ & 1 & 507 & Risk Ratio (M-H, Fixed, 95\% Cl) & $1.72[0.86,3.41]$ \\
\hline $\begin{array}{l}15 \text { Cerebral palsy at or after } 2 \text { years } \\
\text { of age }\end{array}$ & 1 & 507 & Risk Ratio (M-H, Fixed, 95\% Cl) & $5.88[1.33,26.02]$ \\
\hline
\end{tabular}




\begin{tabular}{lllll}
\hline Outcome or subgroup title & No. of studies & $\begin{array}{l}\text { No. of partici- } \\
\text { pants }\end{array}$ & Statistical method & Effect size \\
\hline $\begin{array}{l}16 \text { Death or severe disability 6-13 } \\
\text { years }\end{array}$ & 1 & 302 & Risk Ratio (M-H, Fixed, 95\% Cl) & $0.82[0.48,1.40]$ \\
\hline $\begin{array}{llll}17 \text { Kaufman-ABC MPC } \\
\text { 18 Caesarean delivery }\end{array}$ & 1 & 269 & $\begin{array}{l}\text { Mean Difference (IV, Fixed, 95\% } \\
\text { Cl) }\end{array}$ & $-1.0[-4.47,2.47]$ \\
\hline $\begin{array}{l}19 \text { Subgroup analysis: death or dis- } \\
\text { ability at or after 2 years of age }\end{array}$ & 1 & 547 & Risk Ratio (M-H, Fixed, 95\% Cl) & $1.15[1.07,1.24]$ \\
\hline $\begin{array}{l}19.1 \text { 24-30 weeks' gestation } \\
19.2 \text { 31-36 weeks }\end{array}$ & 1 & 573 & Risk Ratio (M-H, Fixed, 95\% Cl) & $1.21[0.81,1.80]$ \\
\hline
\end{tabular}

Analysis 1.1. Comparison 1 Immediate delivery versus deferred delivery, Outcome 1 Extended perinatal mortality.

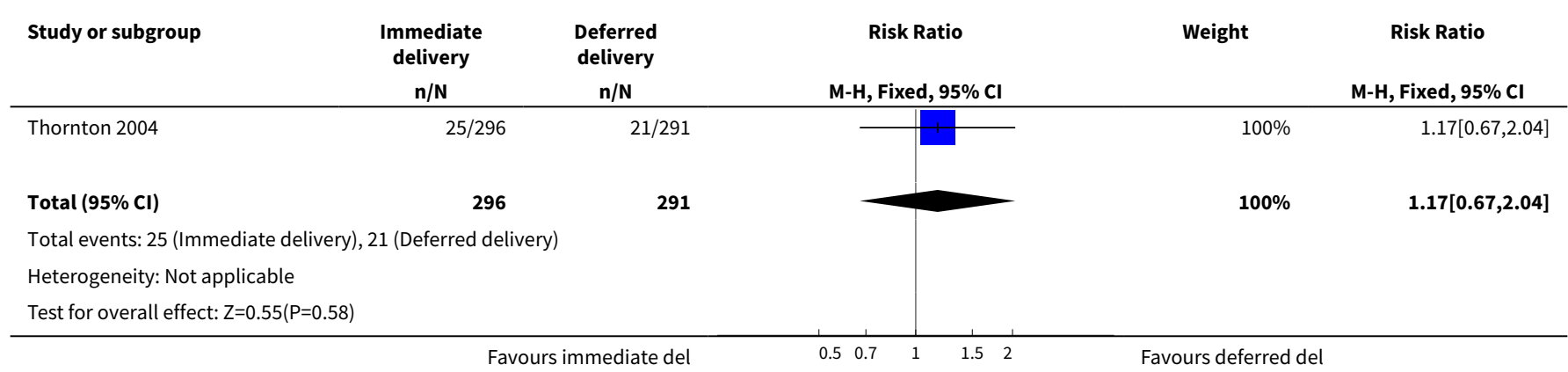

\section{Analysis 1.2. Comparison 1 Immediate delivery versus deferred delivery, Outcome 2 Death or disability at or after 2 years.}

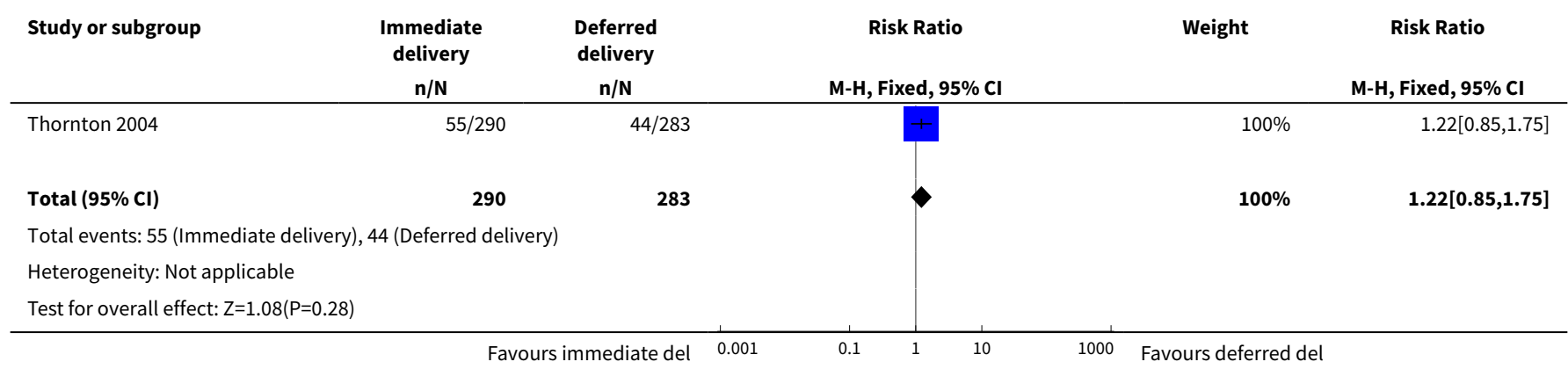


Analysis 1.3. Comparison 1 Immediate delivery versus deferred delivery, Outcome 3 Stillbirth.

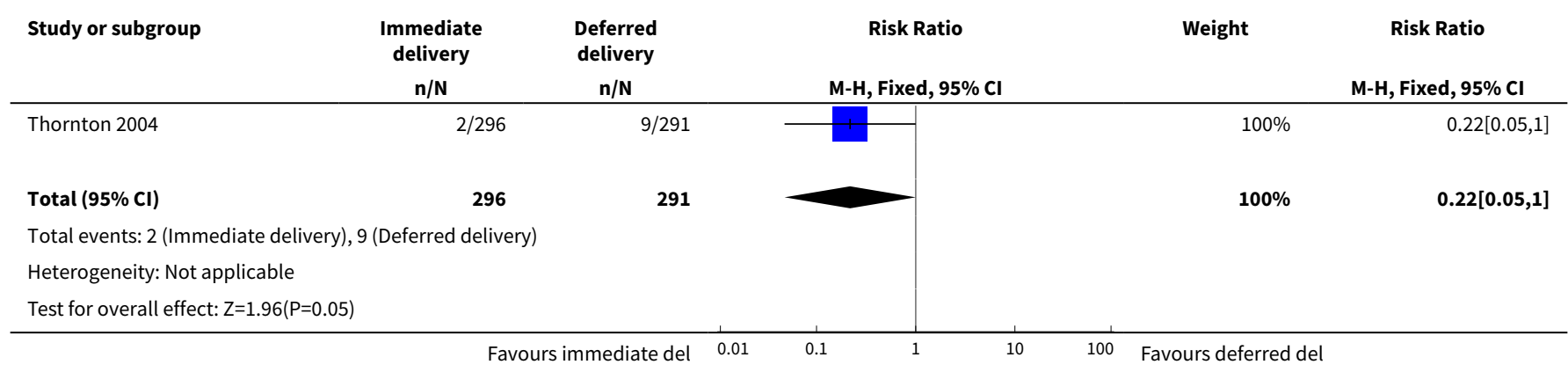

Analysis 1.4. Comparison 1 Immediate delivery versus deferred delivery, Outcome 4 Neonatal mortality.

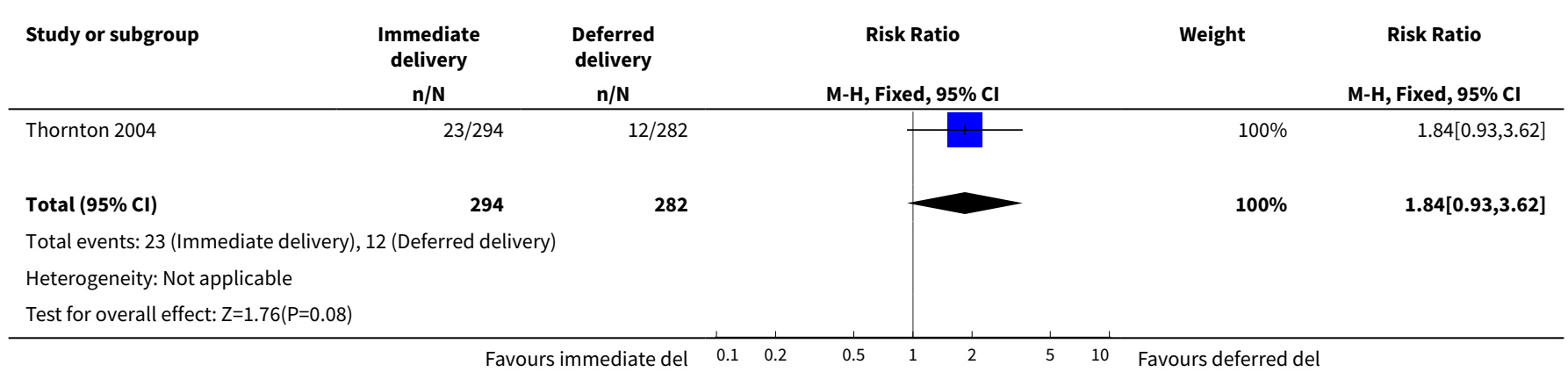

Analysis 1.5. Comparison 1 Immediate delivery versus deferred delivery, Outcome 5 Postneonatal mortality ( $>28$ days to discharge).

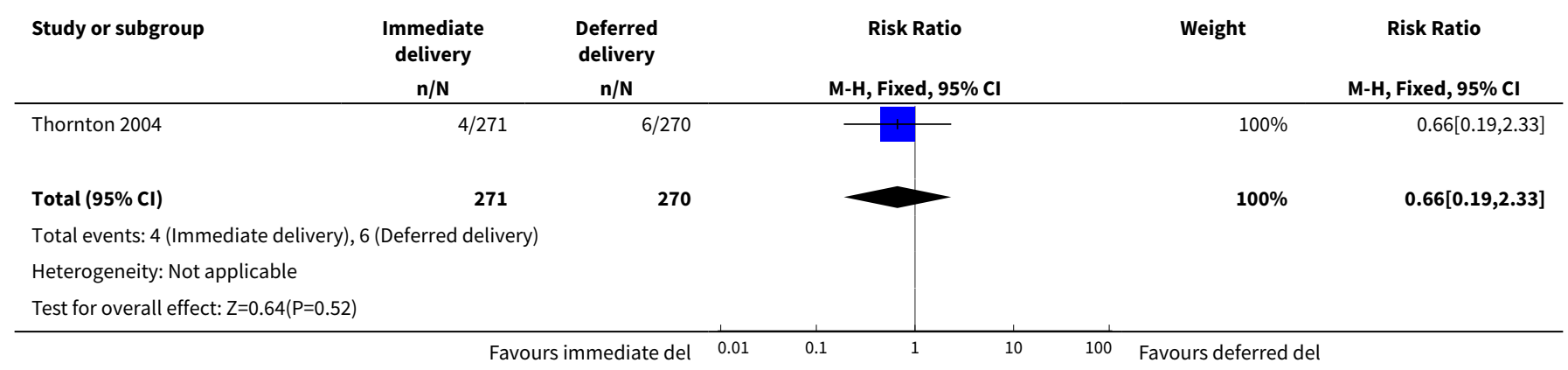

Analysis 1.6. Comparison $1 \mathrm{Immediate}$ delivery versus deferred delivery, Outcome 6 Death at or after 2 years of age.

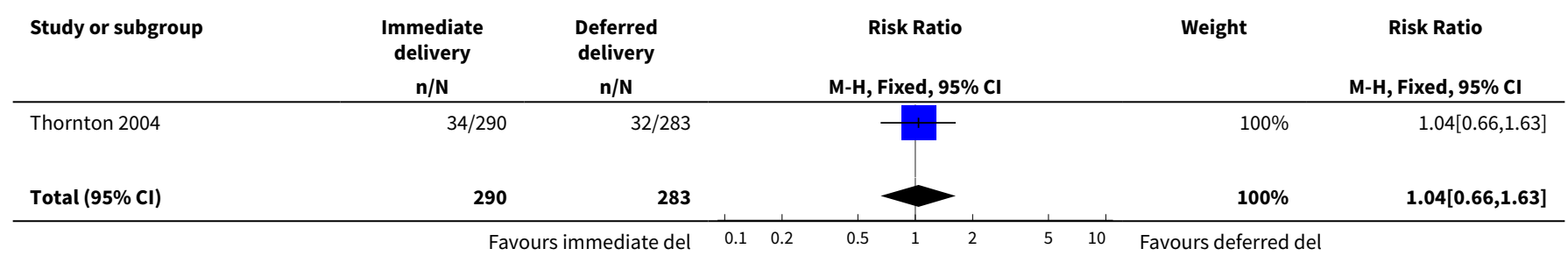




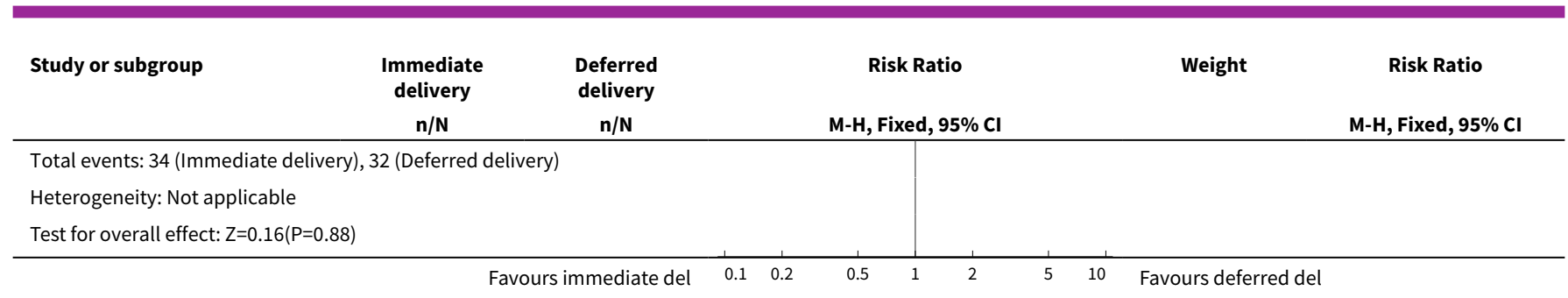

Analysis 1.7. Comparison 1 Immediate delivery versus deferred delivery, Outcome 7 Cord pH less than 7.0.

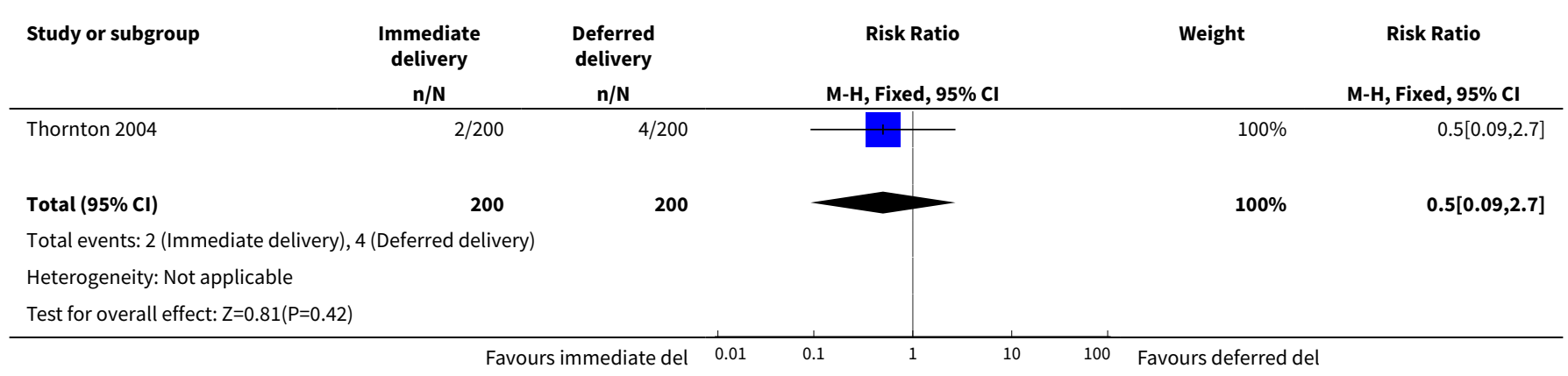

Analysis 1.8. Comparison 1 Immediate delivery versus deferred delivery, Outcome 8 Apgar less than 7 at 5 minutes.

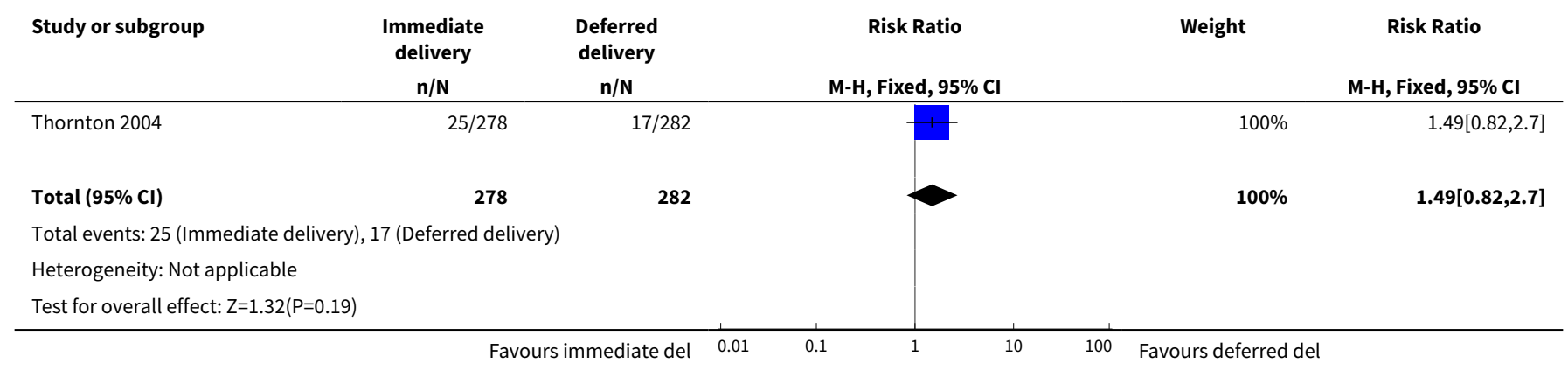

Analysis 1.9. Comparison 1 Immediate delivery versus deferred delivery, Outcome 9 Ventilation $>24$ hours.

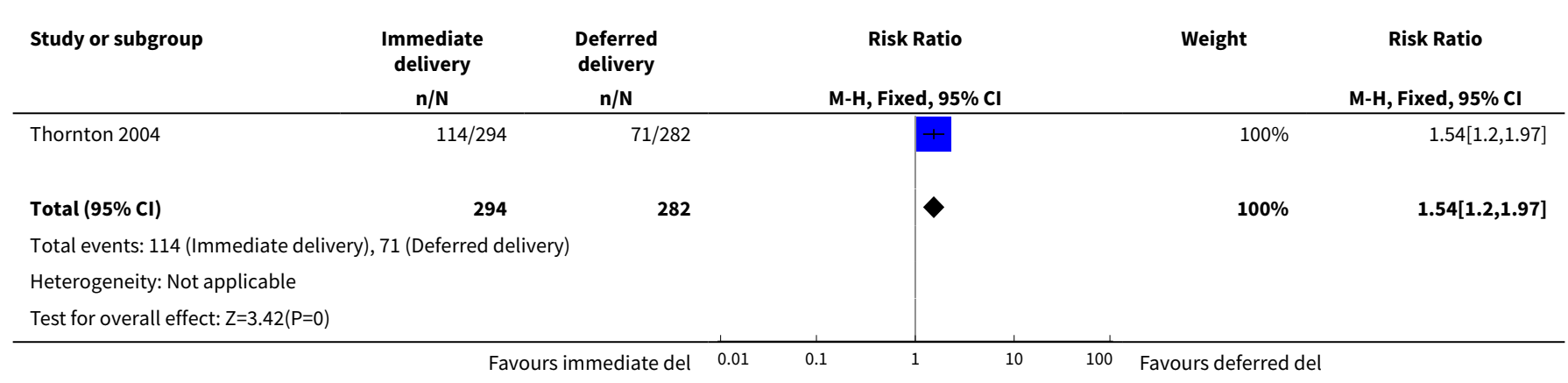


Analysis 1.10. Comparison 1 Immediate delivery versus deferred delivery, Outcome 10 Convulsions.

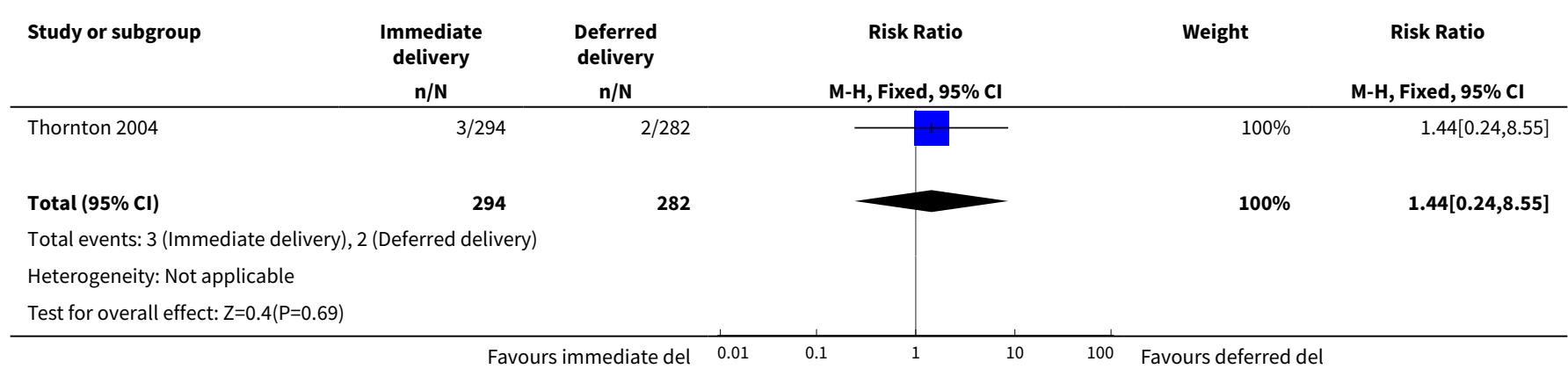

Analysis 1.11. Comparison 1 Immediate delivery versus deferred delivery, Outcome 11 Interventricular haemorrhage or germinal matrix haemorrhage.

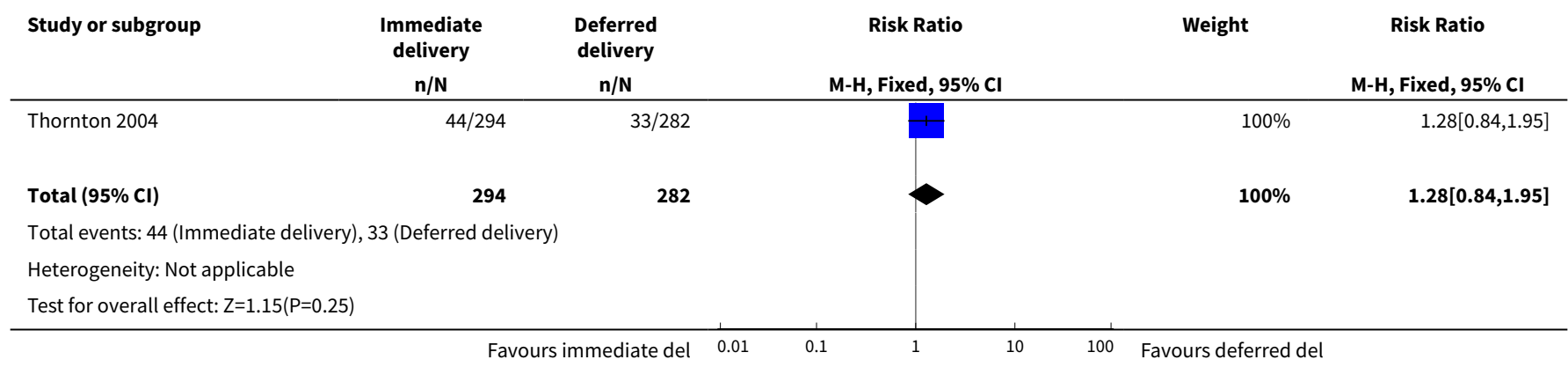

\section{Analysis 1.12. Comparison 1 Immediate delivery versus deferred delivery, Outcome 12 Necrotising enterocolitis.}

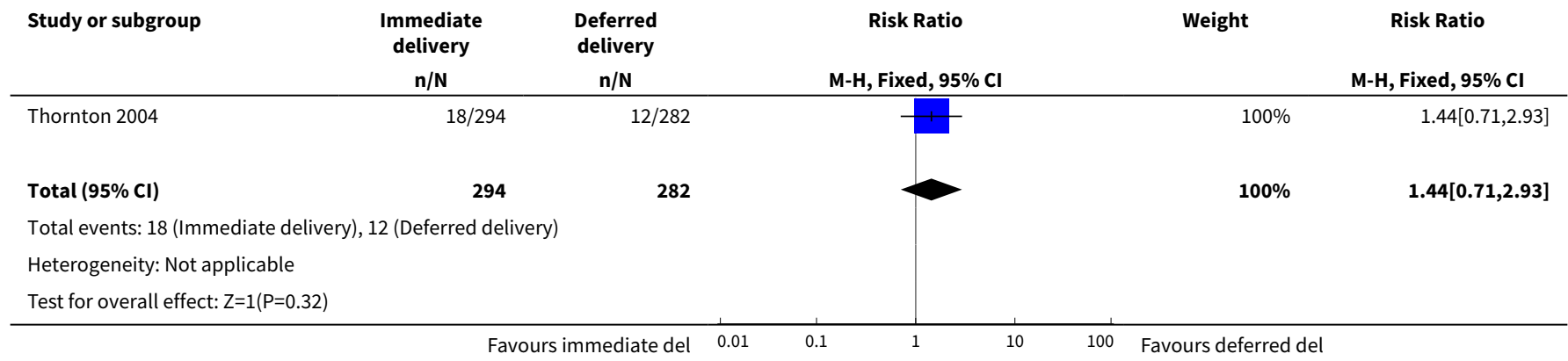

Analysis 1.13. Comparison 1 Immediate delivery versus deferred delivery, Outcome 13 Periventricular leucomalacia or ventriculomegaly.

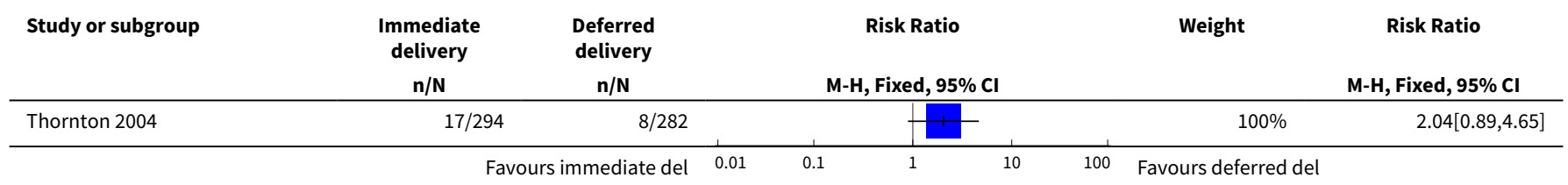




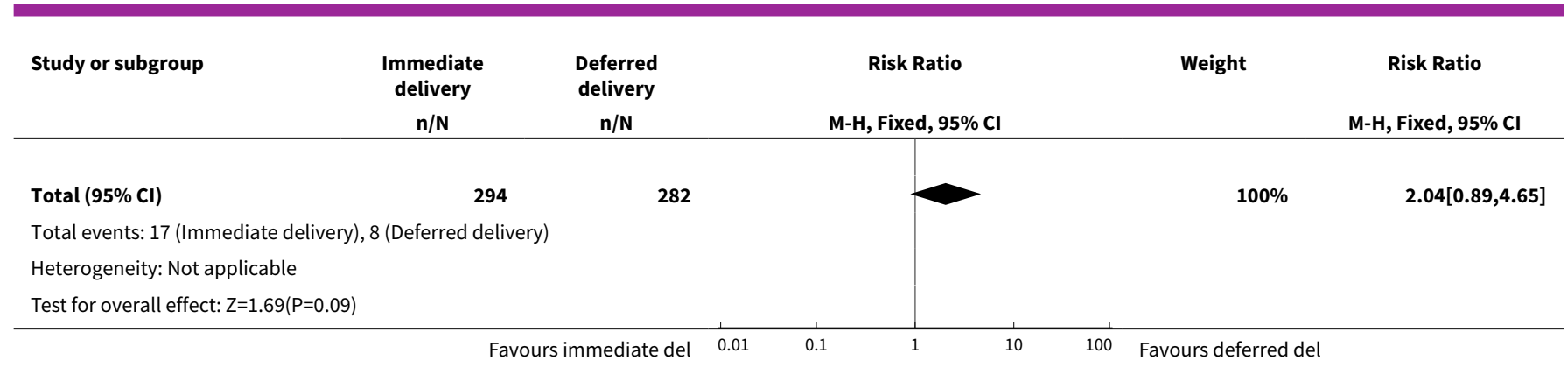

Analysis 1.14. Comparison 1 Immediate delivery versus deferred delivery, Outcome 14 Neurodevelopmental impairment at or after 2 years.

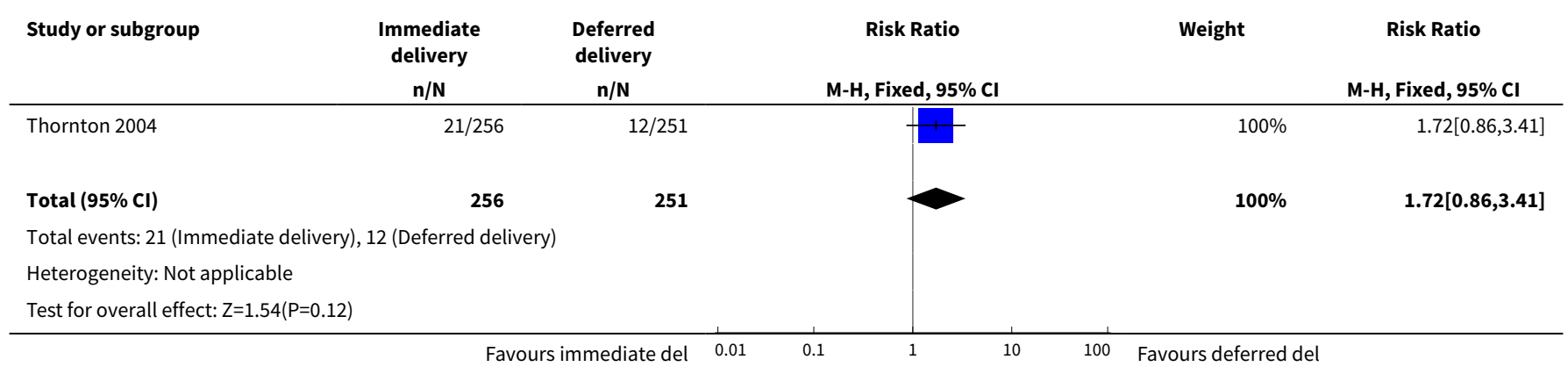

Analysis 1.15. Comparison 1 Immediate delivery versus deferred delivery, Outcome 15 Cerebral palsy at or after 2 years of age.

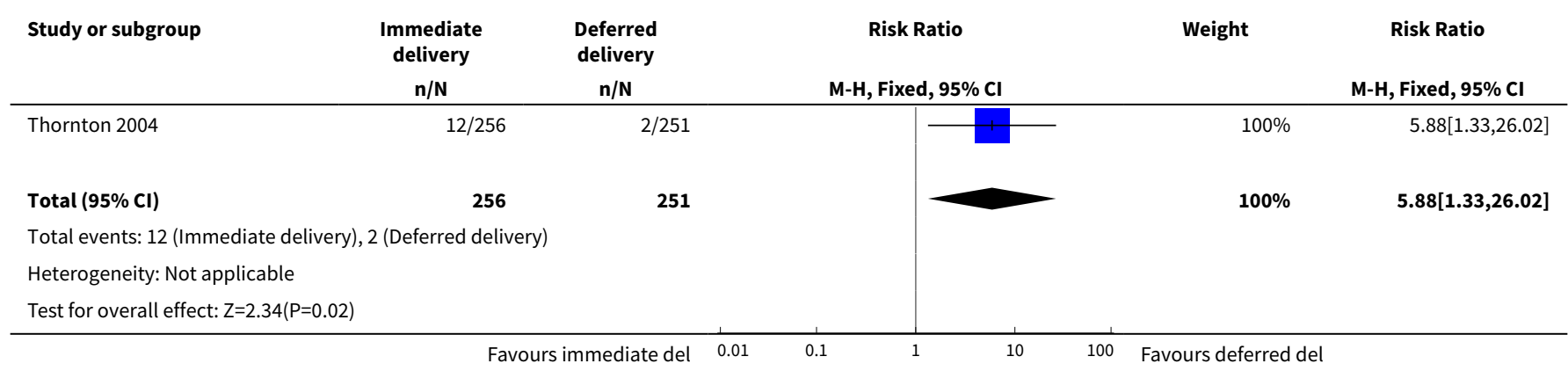

Analysis 1.16. Comparison 1 Immediate delivery versus deferred delivery, Outcome 16 Death or severe disability 6-13 years.

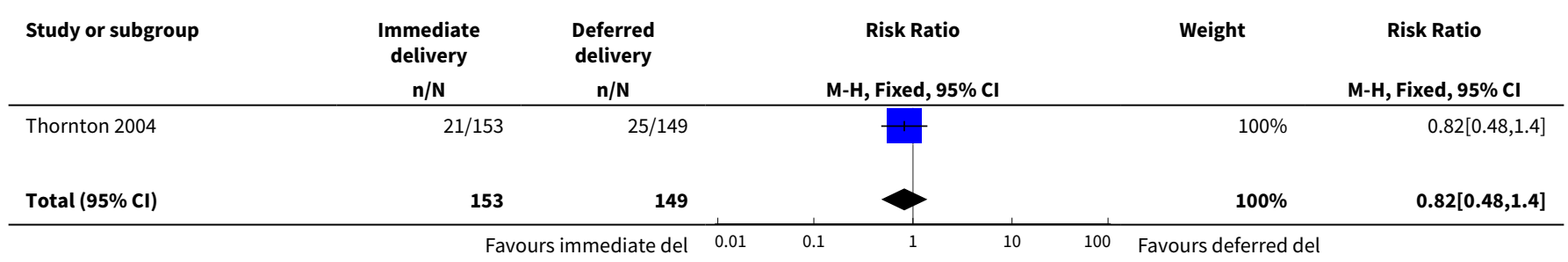




\begin{tabular}{|c|c|c|c|c|c|}
\hline \multirow[t]{2}{*}{ Study or subgroup } & $\begin{array}{l}\text { Immediate } \\
\text { delivery }\end{array}$ & $\begin{array}{l}\text { Deferred } \\
\text { delivery }\end{array}$ & Risk Ratio & Weight & Risk Ratio \\
\hline & $n / N$ & $n / N$ & M-H, Fixed, 95\% Cl & & $\mathrm{M}-\mathrm{H}$, Fixed, $95 \% \mathrm{Cl}$ \\
\hline
\end{tabular}

Total events: 21 (Immediate delivery), 25 (Deferred delivery)

Heterogeneity: Not applicable

Test for overall effect: $\mathrm{Z}=0.74(\mathrm{P}=0.46)$

$\begin{array}{lllllll}\text { Favours immediate del } & 0.01 & 0.1 & 1 & 10 & 100 & \text { Favours deferred del }\end{array}$

Analysis 1.17. Comparison 1 Immediate delivery versus deferred delivery, Outcome 17 Kaufman-ABC MPC.

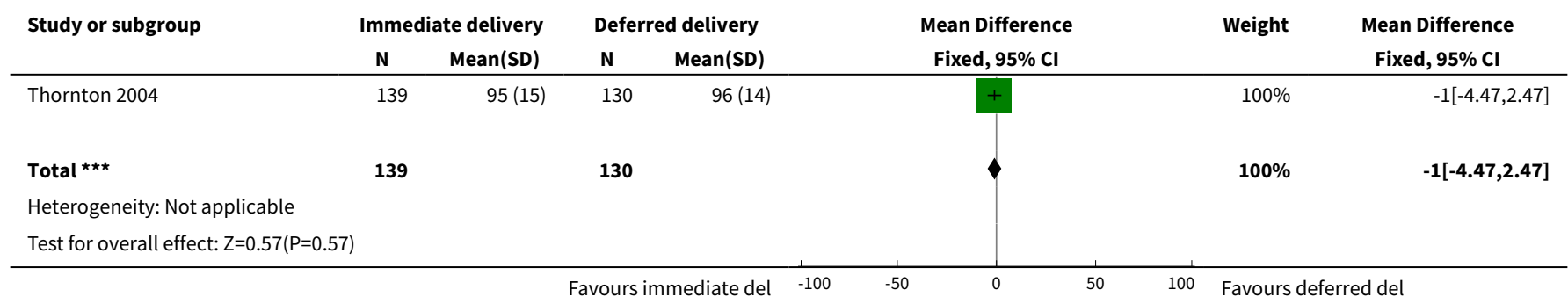

Analysis 1.18. Comparison 1 Immediate delivery versus deferred delivery, Outcome 18 Caesarean delivery.

\begin{tabular}{|c|c|c|c|c|c|}
\hline Study or subgroup & $\begin{array}{c}\text { Immediate } \\
\text { delivery } \\
n / N\end{array}$ & $\begin{array}{c}\text { Deferred } \\
\text { delivery } \\
n / N\end{array}$ & $\begin{array}{c}\text { Risk Ratio } \\
\text { M-H, Fixed, 95\% Cl }\end{array}$ & Weight & $\begin{array}{c}\text { Risk Ratio } \\
\text { M-H, Fixed, } 95 \% \mathrm{CI}\end{array}$ \\
\hline Thornton 2004 & $249 / 273$ & $217 / 274$ & - & $100 \%$ & $1.15[1.07,1.24]$ \\
\hline Total $(95 \% \mathrm{Cl})$ & 273 & 274 & & $100 \%$ & $1.15[1.07,1.24]$ \\
\hline \multicolumn{6}{|c|}{ Total events: 249 (Immediate delivery), 217 (Deferred delivery) } \\
\hline Test for overall effect & & & & & \\
\hline
\end{tabular}

Analysis 1.19. Comparison 1 Immediate delivery versus deferred delivery, Outcome 19 Subgroup analysis: death or disability at or after 2 years of age.

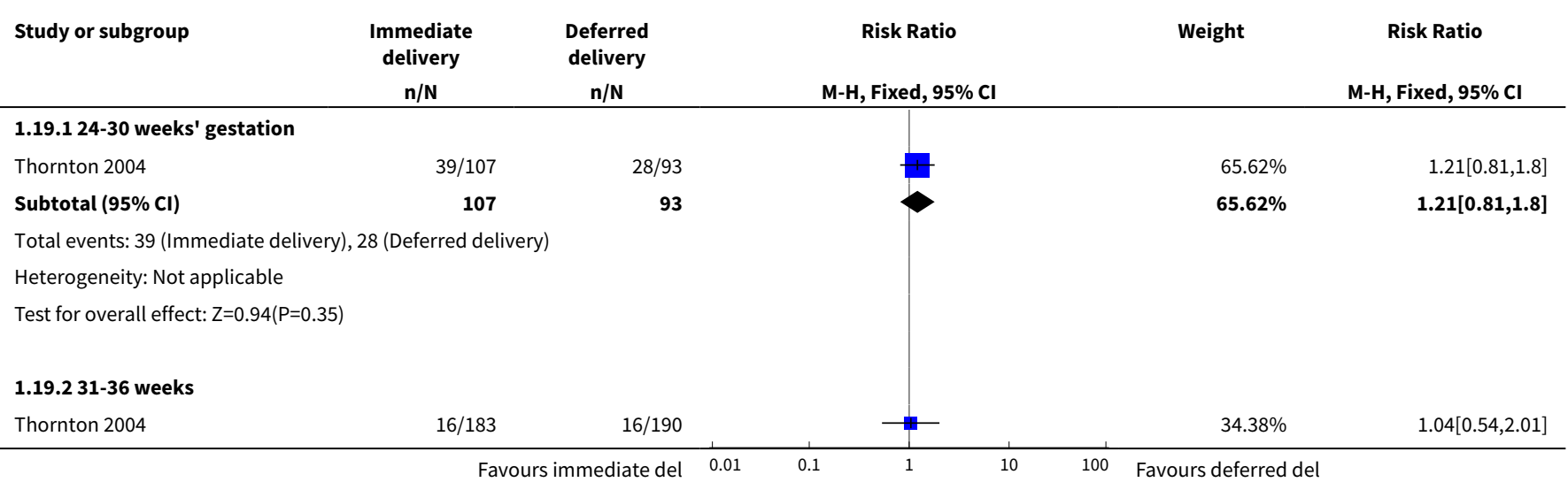




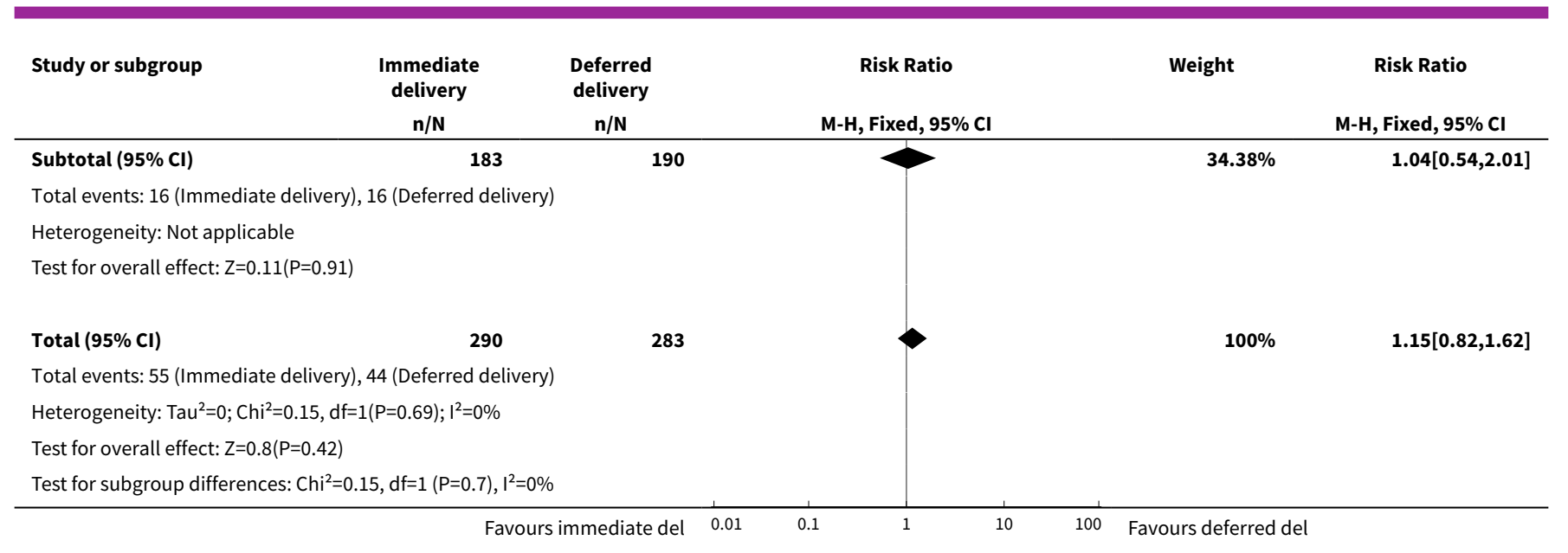

WHAT'S NEW

\begin{tabular}{lll}
\hline Date & Event & Description \\
\hline 30 April 2016 & New search has been performed & Search updated. No new trials identified. \\
& $\begin{array}{l}\text { We have used the GRADE approach to assess the quality of the } \\
\text { body of evidence and included a Summary of findings for the } \\
\text { main comparison. }\end{array}$ \\
& Helen West has been added as an author for this update. \\
\hline
\end{tabular}

30 April $2016 \quad \begin{aligned} & \text { New citation required but conclusions } \\ & \text { have not changed }\end{aligned}$

\section{CONTRIBUTIONS OF AUTHORS}

Sarah Stock is guarantor for the review. All authors contributed to design of the protocol. Sarah Stock contributed to writing the review update, and all authors provided comments on this update.

Helen West restructured the background and plain language summary, updated the methods, carried out GRADE assessments and created the Summary of findings table for this update.

\section{DECLARATIONS OF INTEREST}

Sarah Stock has received grants (paid to her institution) from NIHR HTA, SPARKS, the British Maternal and Fetal Medicine Society, and Tommy's in order to research into preterm labour and stillbirth. She has received payment (to her institution) in respect of travel expenses, accommodation and meeting costs as invited speaker about research at conferences and meetings.

Leanne Bricker - none known.

Jane Norman has received a grant of $£ 11,000$ (paid to her institution) from the Chief Scientist's Office, Scottish Executive, for an epidemiological study entitled: "Ferguson EF, Norman JE, Chalmers J, Shanks E, Finlayson A. Investigation of the beneficial and adverse effects of induction of labour." Jane Norman's has received a number of research grants (paid to her institution) to support research into improving perinatal outcome - none specifically related to immediate vs deferred delivery. Jane has also received small amounts of money for speaking at meetings about prematurity but not immediate vs deferred delivery.

Helen West is paid to work on Cochrane reviews by a grant to Cochrane Pregnancy and Childbirth. The views and opinions expressed therein are those of the authors and do not necessarily reflect those of the Systematic Reviews Programme, NIHR, NHS or the Department of Health. 


\section{SOURCES OF SUPPORT}

\section{Internal sources}

- (HW) Cochrane Pregnancy and Childbirth Group, Department of Women's and Children's Health, The University of Liverpool, Liverpool, UK.

\section{External sources}

- (HW) National Institute for Health Research (NIHR), UKNIHR Cochrane Programme Grant Project: 13/89/05 - Pregnancy and childbirth systematic reviews to support clinical guidelines, UK.

\section{DIFFERENCES BETWEEN PROTOCOL AND REVIEW}

Helen West has been added as an author.

The Methods section has been updated.

The definition of the primary outcome perinatal mortality (intrauterine death or death in the first seven days of life) was amended to represent extended perinatal mortality (intrauterine death or death in the first 28 days of life), as deaths in the neonatal period are frequently secondary to obstetric causes, and these were felt to be relevant.

We also reported the following nonpre-specified outcomes that we considered to be important: death at or after two years of age; KaufmanAssessment Battery for Children Mental Processing Component Score in childhood; death or severe disability in childhood; ventilation for more than 24 hours.

\section{Subgroup analyses}

We changed the subgroup analyses that we planned to undertake from:

1. Gestation less than 28 weeks, 28 to $31+6$ weeks, 32 to 36 weeks.

2. Singleton and multiple pregnancies.

3. Male and female babies.

4. Underlying cause of fetal compromise: placental insufficiency, congenital abnormality, isoimmunisation, intrauterine infection.

5. Severity of fetal compromise: positive end diastolic flow in umbilical artery Doppler, absent or reversed end-diastolic flow in umbilical artery Doppler, abnormal arterial or venous Doppler.

to

1. Gestational age.

2. Multiple and singleton pregnancies.

3. Method of diagnosis of suspected compromise.

We were unable to carry out planned subgroup analyses for multiple and singleton pregnancies and method of diagnosis of suspected compromise as the data were not reported by the subgroups of multiple and singleton pregnancies or method of diagnosis of suspected compromise.

We had intended to perform subgroup analyses for gestations less than 28 weeks, 28 to $31+6$ weeks and 32 to 36 weeks. Data were not available for the groups specified but were available for gestations 24 to 30 weeks and gestations 31 to 36 weeks. As the effect of gestation could be important, we performed post hoc subgroup analysis for these groups.

We were unable to carry out planned subgroup analyses for the following two outcomes extended perinatal mortality (intrauterine death or death in the first 28 days of life) and serious neonatal morbidity (composite outcome including BPD, NEC, IVH, ROP, HIE) as data were not reported.

\section{Sensitivity analyses}

We were unable to undertake our planned sensitivity analyses as only one trial was included.

\section{Data synthesis}

We were unable to combine data in meta-analysis as only one study was included

For this update, we have used the GRADE approach to assess the quality of the body of evidence and this is summarised in Summary of findings for the main comparison. 


\section{N D EX TERMS}

\section{Medical Subject Headings (MeSH)}

*Infant, Premature; Cerebral Palsy [etiology]; Cesarean Section [statistics \& numerical data]; Delivery, Obstetric [adverse effects] [ ${ }^{\star}$ methods]; Fetal Distress [ ${ }^{\star}$ complications]; Infant Mortality; Randomized Controlled Trials as Topic; Respiration, Artificial [statistics \& numerical data]; Watchful Waiting

\section{MeSH check words}

Female; Humans; Infant; Infant, Newborn; Pregnancy 